\title{
Testing and Analysis Validation of a Metallic Repair Applied to a PRSEUS Tension Panel
}

\author{
Adam Przekop ${ }^{1}$ \\ Analytical Mechanics Associates, Inc., Hampton, VA 23666 \\ Dawn C. Jegley ${ }^{2}$ \\ NASA Langley Research Center, Hampton, VA 23681
}

\begin{abstract}
A design and analysis of a repair concept applicable to a stiffened composite panel based on the Pultruded Rod Stitched Efficient Unitized Structure was recently completed. The damage scenario considered was a midbay-to-midbay saw-cut with a severed stiffener, flange and skin. Advanced modeling techniques such as mesh-independent definition of compliant fasteners and elastic-plastic material properties for metal parts were utilized in the finite element analysis supporting the design effort. A bolted metallic repair was selected so that it could be easily applied in the operational environment. The present work describes results obtained from a tension panel test conducted to validate both the repair concept and finite element analysis techniques used in the design effort. The test proved that the proposed repair concept is capable of sustaining load levels that are higher than those resulting from the current working stress allowables. This conclusion enables upward revision of the stress allowables that had been kept at an overly-conservative level due to concerns associated with repairability of the panels. Correlation of test data with finite element analysis results is also presented and assessed.
\end{abstract}

\section{Introduction}

$\mathrm{T}$ he primary structural concept being pursued as an important component of next generation airframe technology under the Environmentally Responsible Aviation (ERA) Project at NASA is the Pultruded Rod Stitched Efficient Unitized Structure (PRSEUS), ${ }^{1-9}$ illustrated in Figure 1. This concept is being developed in a partnership between NASA and The Boeing Company for application to future transport aircraft with the goal of developing lighter structure so that the aircraft will require less fuel and produce fewer pollutants. The PRSEUS structure is highly-integrated, weight-efficient, and has crack-arresting capabilities. In this concept a stitched carbon-epoxy material system is used. By stitching through the thickness of a dry material system, the labor associated with panel fabrication and assembly can be significantly reduced. When stitching through the thickness of pre-stacked skin, stringers and frames, the need for mechanical fasteners is almost eliminated. In addition, stitching reduces delamination and improves damage tolerance, allowing for a lighter structure with more gradual failures than traditional composites without through-the-thickness reinforcement.

The PRSEUS concept consists of carbon-epoxy panels fabricated from dry components stitched together, after which the resin is infused in an oven while the panel is subjected to vacuum pressure. Skins, flanges and webs are composed of layers of carbon material that are pre-kitted into multi-ply stacks. A single stack contains seven plies with stacking sequence $[+45,-45,0,90,0,-45,+45]_{\mathrm{T}}$ where the 0 -degree plies are approximately twice the thickness of the \pm 45 and 90 -degree plies, resulting in a 0.052 in. stack thickness with percentage of the 0,45 and 90 -degree fibers equal to 44.9, 42.9 and 12.2, respectively. Several pre-kitted stacks are used to build up the desired thickness and configuration. Stiffener flanges are stitched to the skin using Vectran thread and no mechanical fasteners are used for joining. To maintain the panel geometry during fabrication, first stiffeners and then the skin are placed in a tool for stitching prior to moving the assembly to a curing tool for consolidation in the oven. The stiffeners running in the axial direction consist of webs with unidirectional carbon fiber rods at the top of the web. The stack material forming the stiffener web overwraps the rod to form the stiffener cap. The stiffeners in the lateral direction are foam-filled hats. The manufacturing process is described in detail in ref. [6].

\footnotetext{
${ }^{1}$ Engineer 5, c/o NASA Langley Research Center, Hampton, VA 23681, Mail Stop 190, Senior Member AIAA.

${ }^{2}$ Senior Aerospace Engineer, Structural Mechanics and Concepts Branch, Mail Stop 190, Associate Fellow AIAA.
} 


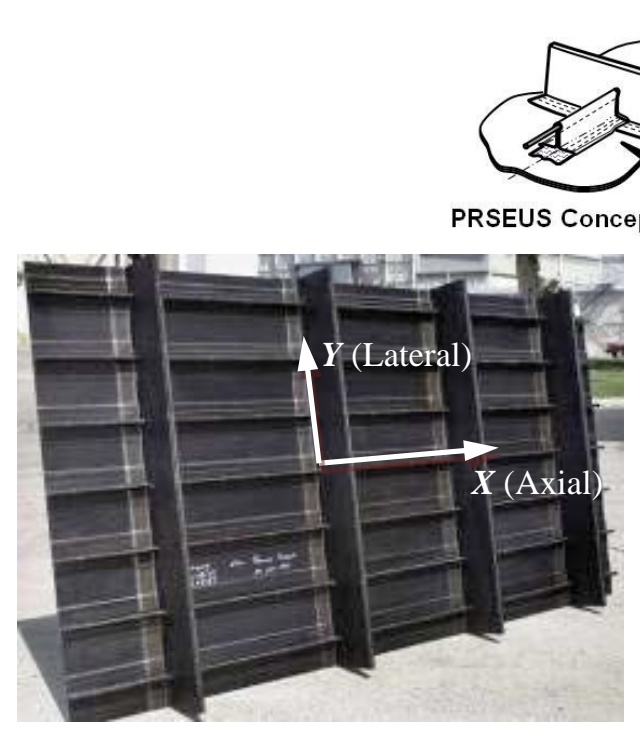

(a)

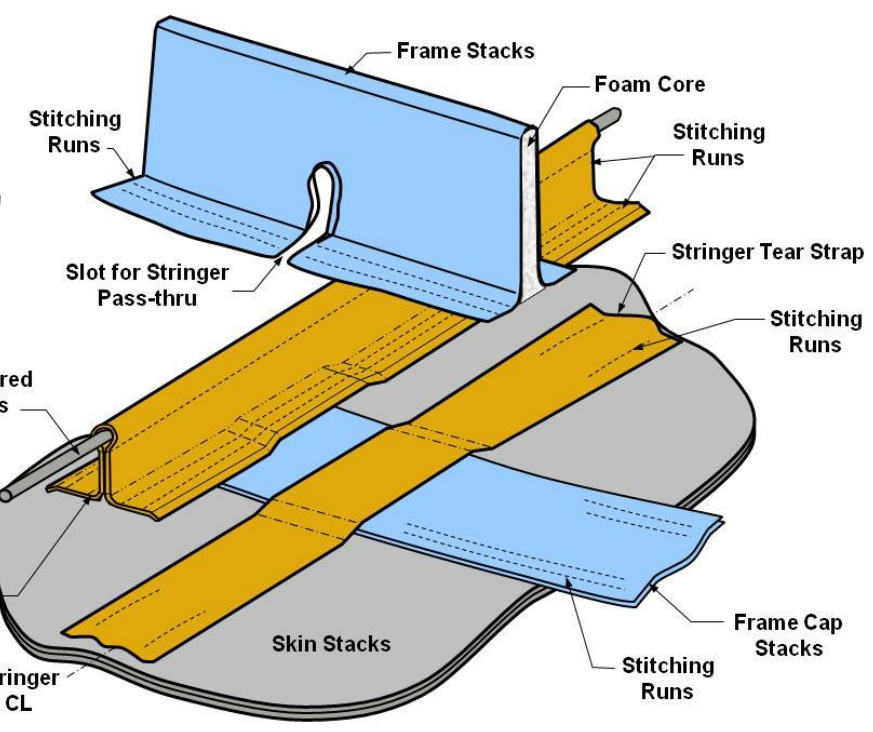

(b)

Figure 1. PRSEUS: (a) sample flat panel and (b) general assembly concept. ${ }^{6}$

While providing unique advantages in weight, damage tolerance and manufacturing, the PRSEUS concept also presents some inherent challenges not shared by conventional metallic airframes. Among these challenges is the need for design concepts for manufacturing joints and repair techniques for rod-stiffened panels. While both manufacturing joints and repair techniques must be light-weight and meet design load requirements, they are typically applied in different environments. While in a factory environment, a large component with extensive damage might be replaced in its entirety. However, in the operational environment the replacement of a large highly-integrated component with localized damage is often cost-inefficient and impractical. In addition, composite technology-based repair such as bonding that requires a tightly controlled environment, perishable supplies, highly skilled workers and advanced tooling to produce a reliable bond may be acceptable in a factory environment but may not be feasible in the field. Since, from a practical standpoint, basic repairs cannot depend on the availability of a factory-like environment, repair techniques applicable to PRSEUS panels in an operational environment were developed. ${ }^{10,11}$

This paper describes the study of a repaired tension PRSEUS panel. First, a brief background regarding the assumed damage, repair objective, repair design and selection of design load levels is provided in section II. Finite element (FE) analysis supporting repair design is described in section III. Test set-up and instrumentation are described in section IV. Results are presented in section $\mathrm{V}$ and include description of the damage development in the panel leading to its final failure, correlation of the finite element (FE) analysis and test results, and revision to the PRSEUS tension working stress allowable that the test enabled. Finally, concluding remarks are offered in section VI.

\section{Damage, Repair, and Requirements}

\section{A. Stringer definition and damage}

The damage scenario considered in this study was a severe but localized damage that can be classified as Category 4 per ref. [12]. Such damage results from a known incident, is obvious to flight crew, limits flight maneuvers and requires immediate repair after flight. The cross-section of a PRSEUS rod-stringer is shown in Figure 2 including the aforementioned stitch lines highlighted with red dashed lines. The panel contains three rodstringers spaced 6 in. apart. The center of the panel was cut mid-bay to mid-bay including all its through-thethickness components, i.e., skin, center stringer flange, web, and pultruded rod. The dimensions of the machined opening were $6 \mathrm{in}$. by $0.25 \mathrm{in}$. It is worthwhile to note that the panel and damage configuration used in the present effort was identical to the one previously used to demonstrate damage arresting capabilities of through-the-thickness stitched composites. ${ }^{8}$ 


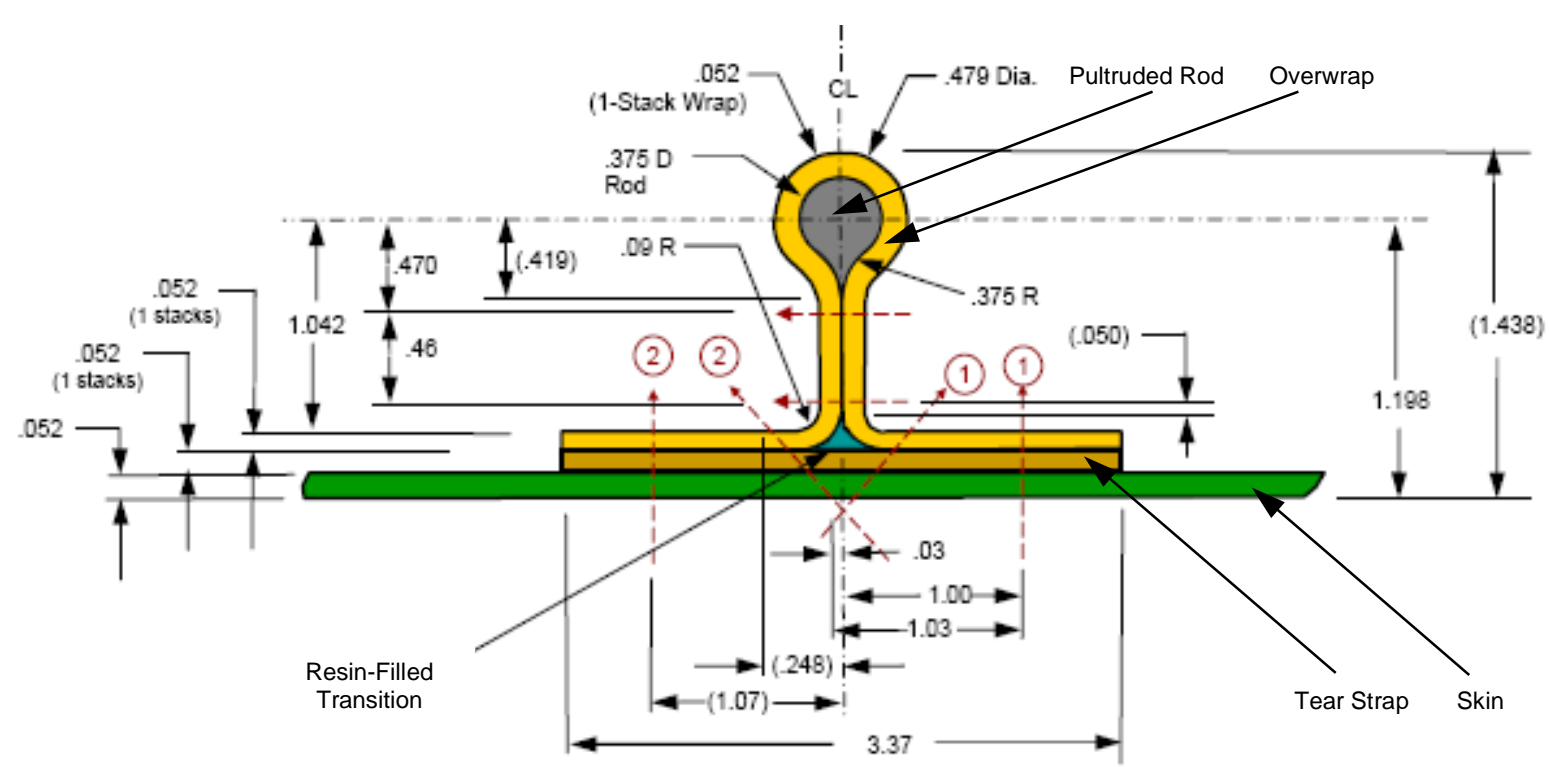

Figure 2. Stringer cross-section. Red arrows indicate stitch lines. Dimensions are in inches.

\section{B. Repair objective}

First and foremost, the repair assembly was required to restore the original load carrying capability of the pristine panel while incurring the smallest weight penalty possible. In general, while not formulated as a quantitative metric, the mechanical behavior and load paths of the repaired panel resembling that of the pristine panel were also required. In addition, established design practices such as those regarding spacing requirements between metallic fasteners applied to a composite primary structure ${ }^{13}$ were followed. Finally, operational factors, e.g. what is practical in the environment that the repair technique is intended to be applied, also influenced the design.

\section{Repair design}

The general repair concept was first proposed by The Boeing Company and its initial exploration was conducted in proprietary studies using simplified models and small test articles. Details of the repair design applied in the current effort were reported in ref. [11]. The overall configuration of the repair is illustrated in Figure 3. Additional details pertaining to fastener sizes and stiffened side repair dimensions are provided in Figure 4. The repair assembly consists of two aluminum alloy stiffened side pieces (also referred to as angles) whose bottom surfaces rest on the center stringer flange surface and the vertical portions are parallel to the stringer web and surround the pultruded rod. These two stiffened side pieces are riveted together above the rod. The clearance between the two pieces and the pultruded rod ensures that the repair is not clamped on the rod. The flange sections of the repair components are bolted through the panel flanges to an aluminum alloy smooth side strap (also referred to as a doubler). The width of this strap extends to both sides such that its edges can be bolted to the flanges of both outside stringers.

Note, that by incorporating a stiff pultruded rod offset from the panel surface, the pristine PRSEUS panels are designed to efficiently carry not only in-plane, but also bending loads. Consequently, the repair concept is designed such that the neutral bending axis of the general cross-section of the three assembled repair pieces (the two stiffened side pieces and the smooth side doubler) coincides with the neutral bending axis of the pristine panel in its general cross-section. This way the repair assembly can transfer combined in-plane and bending loads in a similar fashion as the pristine panel.

Finally, note that the taper of the center stringer is not considered a part of the damage but rather it is a part of the repair design. The repair design requires that loads from the severed stringer be transferred into the repair assembly, yet the stringer web thickness of only 0.104 in. renders bolted attachment through the webs impractical due to very limited bearing surface. Thus, as part of the repair design, the center web and rod are machined such that the loads from the center stringer are diverted into the flange where they can be gradually transferred to the repair by fasteners through the flange. 


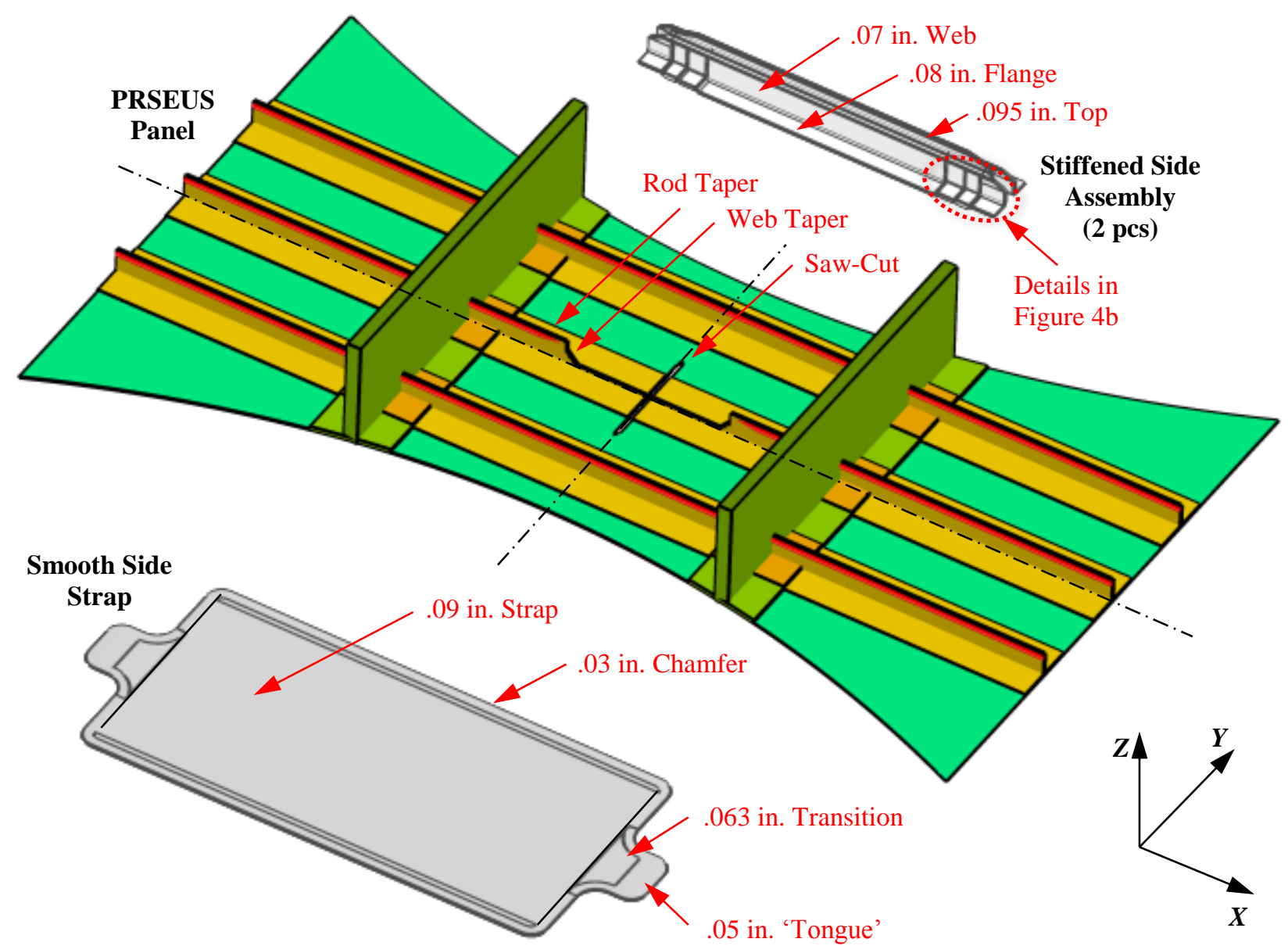

Figure 3. Exploded view of the saw-cut tension PRSEUS panel with bolted metallic repair.

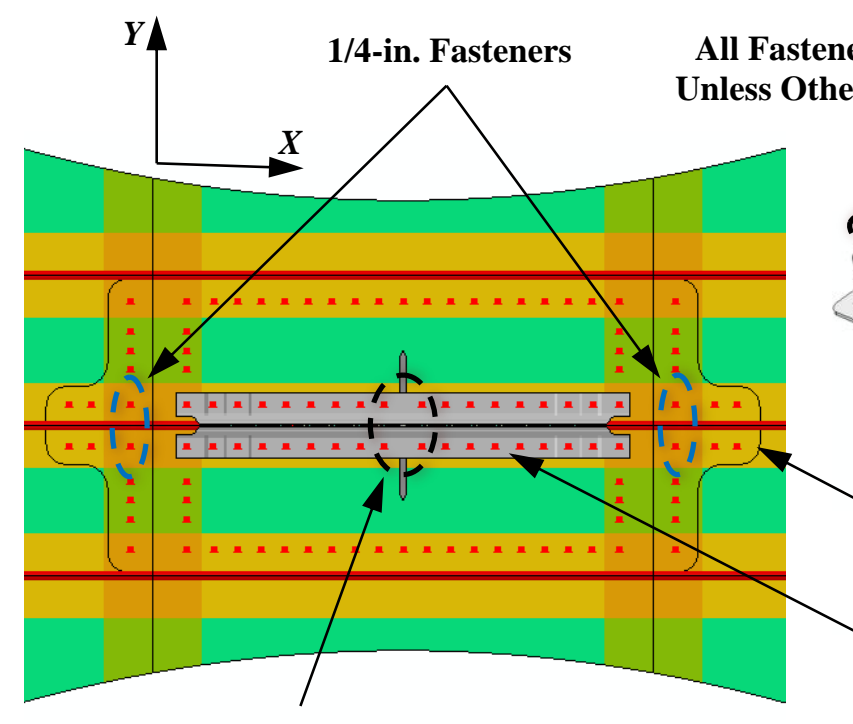

5/32-in. Fasteners
All Fasteners 3/16-in. Unless Otherwise Noted
(2 pcs) 
The smooth side of the test article is shown in Figure 5 and the stiffened side is shown in Figure 6 . These figures present not only the dog bone-shaped test section of the panel presented in Figure 3, but also the load introduction metallic lugs. The span of the dog bone-shaped test section of the panel was $50 \mathrm{in}$. with the foam-filled frames spaced 20 inches apart, as seen in Figure 6. The pin-to-pin length of the specimen was 142 in. The smooth side of the panel after installation of all the strain gages is shown in Figure 5, while the stiffened side of the panel with the repair components and only the strain gages on the severed stringer underneath the repair installed is shown in Figure $6 \mathrm{a}$ and $6 \mathrm{c}$. Finally, a close-up view of the center stringer taper and the saw-cut prior to repair installation are shown in Figure 6b.

\section{Load levels}

Based on previous experience, tension loading was designated as a critical design condition. ${ }^{6,8}$ Airframe certification regulations ${ }^{14}$ specify that metallic components must remain in the elastic regime up to the design limit load (DLL). For load greater than DLL and up to the design ultimate load (DUL), a plastic regime is permitted if the metallic parts do not suffer, or otherwise cause, a catastrophic failure (the latter requirement protects against such conditions as jamming of control surfaces due to excessive plastic regime displacements, even though fracture does not occur). Although not stemming from regulations, an additional conservativeness was imposed on the repair in the current design process in that the repair assembly does not fail before the composite panel itself suffers a failure in a location away from the site of the repair. Therefore, an additional loading level was introduced in addition to DLL (100\% of the design value) and DUL (equal to $150 \%$ of DLL). Namely, a condition of DUL plus $10 \%$ (i.e., 165\% of DLL) was considered. Thus, the PRSEUS panel was required to withstand DUL, but the repair assembly was required to withstand DUL plus $10 \%$. A 60 ksi working stress allowable at $-65^{\circ} \mathrm{F}$ for the pristine panel was adopted in the load calculations. This value was then adjusted to account for testing at room temperature and produced the following values: DLL of $119.1 \mathrm{kip}$, DUL of $178.7 \mathrm{kip}$ and DUL+10\% of $196.5 \mathrm{kip} .{ }^{11}$ Prior to this effort, repair to PRSEUS panels was regarded as a possible limiting condition in panel design. Consequently, a conservative value of $55 \mathrm{ksi}$ working stress allowable was routinely applied in preliminary sizing efforts. ${ }^{6,8}$ The repair design effort assumed a more aggressive $60 \mathrm{ksi}$ working stress allowable to challenge this limitation. In other words, a successful repair design sustaining $60 \mathrm{ksi}$ allowable could enable further mass savings in the primary airframe structure.

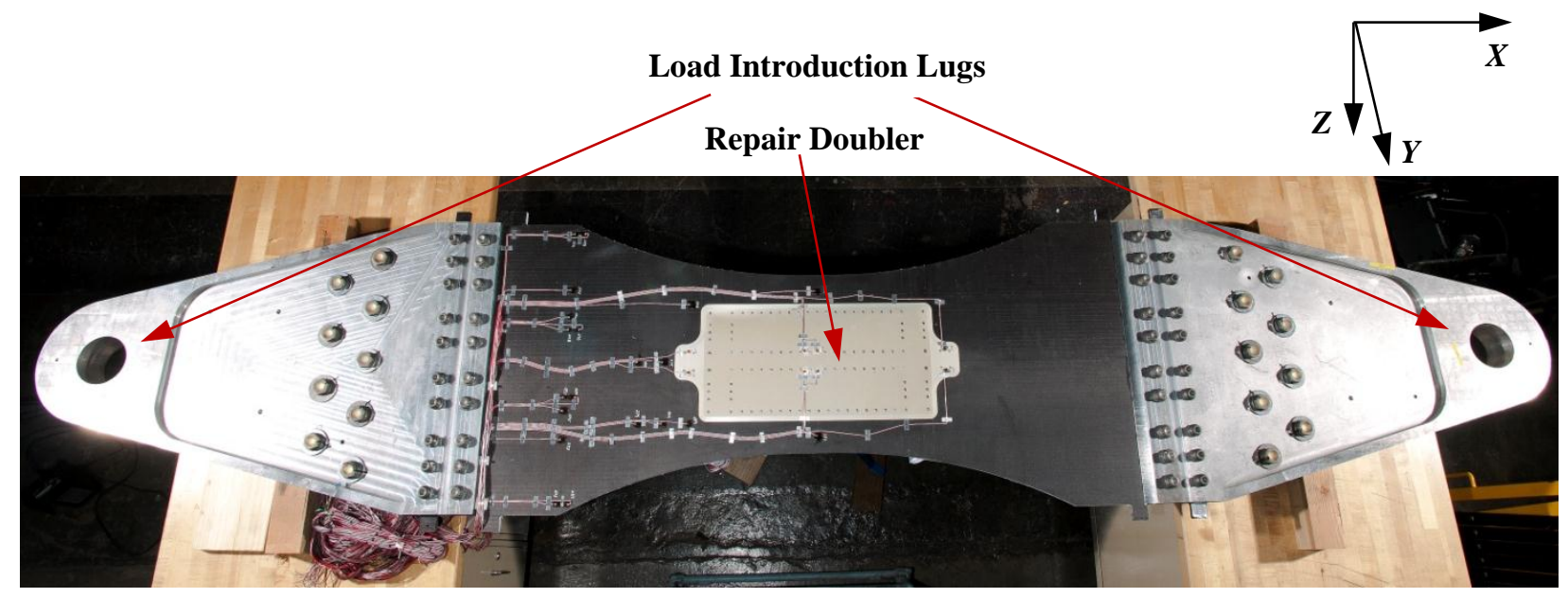

Figure 5. Smooth side view of the tension PRSEUS panel with the repair installed. 


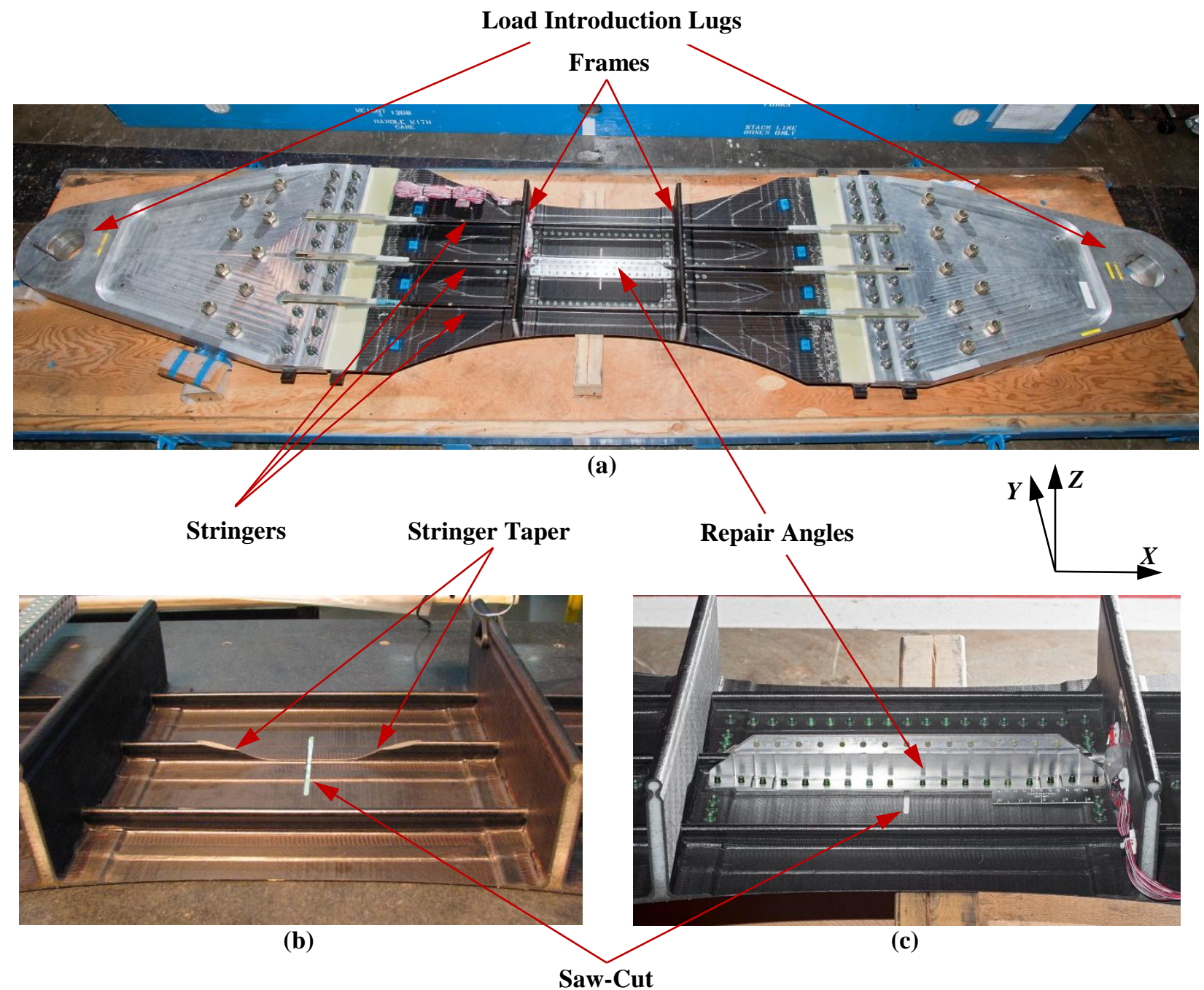

Figure 6. Stiffened side of the tension PRSEUS panel: (a) overall view with the load introduction lugs, (b) center section with the center stringer machined taper before repair assembly installation, and (c) center section with the stiffened side repair assembly installed.

\section{Analysis Approach}

The primary analysis tool in the design effort was FE-based and details of the FE model were reported in ref. [11]. To recap briefly, a model of the dog bone section of the PRSEUS panel, as seen in Figure 3, was developed in the commercial FE code Abaqus. ${ }^{15}$ The model was discretized using four-node S4R shell elements for all of its components except the pultruded rods which were modeled using two-node B31 beam elements. The stack of material overwrapping the pultruded rods was not explicitly modeled. Instead, the entire web was modeled as a planar surface and one line of shell element edges and beam elements were collocated sharing the same subset of nodes. The repair assembly parts were also discretized using primarily S4R shell elements and few three-node S3 elements. A typical element edge length was approximately 0.2 in.

Holes to accommodate fasteners were not modeled. Fasteners were modeled using two-node CONN3D2 connector elements with their stiffness components computed externally using the Huth Hi-Lok formulation available in Nastran ${ }^{16}$ and assigned to aforementioned connector element property definitions. Note that a single fastener element models a connection between two surfaces, and consequently suffices to model a single-shear fastener. When one fastener joins together three surfaces, i.e., acts as a double-shear fastener, two connector elements defined in series are needed. Therefore, to model the total of 129 fasteners, 36 of which are double shear fasteners as illustrated in Figure 4, the total number of connector elements required was 165. Overall, the FE model contained 40,443 nodes and 242,658 degrees of freedom. 
Aluminum alloy elastic-plastic material properties, modeled as a bi-linear (elastic, perfectly plastic) stress-strain relationship, were utilized in the repair assembly. All composite material properties were modeled as elastic only. Fasteners were not permitted to exceed their yield stress values, so titanium alloy was also assigned only elastic material properties for the purpose of fastener stiffness calculations. Assumed material properties are presented in Table 1.

Table 1. Material properties.

\begin{tabular}{ccccc}
\hline \hline Material & $\begin{array}{c}\mathrm{E}_{1}, \mathrm{Msi} \\
\left(\mathrm{H}_{1}, \mathrm{ksi}\right)\end{array}$ & $\begin{array}{c}\mathrm{E}_{2}, \mathrm{Msi} \\
\left(\mathrm{H}_{2}, \mathrm{ksi}\right)\end{array}$ & $v_{12}$ & $\mathrm{G}_{12}, \mathrm{Msi}$ \\
\hline $\begin{array}{c}\text { Rod Toray } \\
\text { T800/3900-2B }\end{array}$ & 16.1 & & 0.30 & 6.19 \\
\hline $\begin{array}{c}\text { AS4-VRM34 } \\
\text { (Stack Properties) }\end{array}$ & 9.74 & 4.86 & 0.40 & 2.37 \\
\hline $\begin{array}{c}\text { Foam Core } \\
\text { Rohacell 110WF }\end{array}$ & 0.021 & 0.021 & 0.32 & 0.008 \\
\hline $\begin{array}{c}\text { Aluminum Alloy } \\
\text { 7075-T6 }\end{array}$ & $\begin{array}{c}10.3 \\
(60.5)\end{array}$ & $\begin{array}{c}10.3 \\
(60.5)\end{array}$ & 0.33 & 3.87 \\
\hline $\begin{array}{c}\text { Titanium Alloy } \\
\text { Ti-6Al-4V Grade 5 }\end{array}$ & 16.5 & 16.5 & 0.342 & 6.38 \\
\hline \hline
\end{tabular}

As mentioned before, the 50-in.-long dog bone-shaped PRSEUS test panel was modeled. The metallic load introduction lugs, shown in Figure 5 and Figure 6, were designed to produce a uniform in-plane displacement across the panel width at the ends of this section and, therefore, were not modeled. Consequently, the force distribution across the panel width at its end stations was not known a priori. Thus, by constraining one end of the panel and applying a uniform in-plane displacement at the other end, and interrogating the resultant reaction force at the boundary, the desired enforced in-plane displacements were determined in the iterative fashion. For the three prescribed loadings levels discussed in section II.D, i.e., DLL of $119.1 \mathrm{kip}$, DUL of $178.7 \mathrm{kip}$ and DUL+10\% of $196.5 \mathrm{kip}$, the corresponding uniform in-plane displacements of $0.2042 \mathrm{in} ., 0.3048 \mathrm{in}$. and $0.3353 \mathrm{in}$. were found, respectively.

Finally, the FE model did not incorporate features required to predict a damage progression, such as delamination, surface splitting or through-the-thickness crack origination and propagation. This level of FE analysis fidelity is computationally very taxing and, therefore, is not a customary approach in design efforts.

\section{Experimental Setup and Instrumentation}

The panel was tested at the NASA Langley Research Center (LaRC) in the one-million-pound-load-rated test machine, as shown in Figure 7. The test was conducted at room temperature. The tension load was applied through displacement-control and was introduced at the rate of $0.05 \mathrm{in.} / \mathrm{min}$. The load was held constant for approximately 5 seconds at levels deemed significant, including the load levels introduced in section II.D. After achieving all the load levels that the panel was designed to sustain, it was loaded until final failure.

The panel was instrumented with 89 strain gages comprising of 85 unidirectional gages and four rosettes, and two direct current displacement transducers (DCDTs). Three visual image correlation (VIC-3D) systems ${ }^{17}$ and three video recordings were also used to monitor panel behavior.

The strain gage locations are presented in Figure 8. Strain gages were placed to capture strain levels in the highly-loaded sections of the panel and the repair assembly. Additionally, gages were positioned to assess the uniformity and/or symmetry of the load introduction from the lugs and the far field panel section into the test section. The two displacements measured with the DCDTs were lengthening pin-to-pin and in the 50-inch dog bone-shaped section. Two global VIC-3D systems captured full-field responses of the panel between the load introduction lugs on both smooth and stiffened sides of the panel, where the panel surface was not obstructed by sensors or wiring. The third VIC-3D system captured high-resolution images of the stiffened side of the panel in the vicinity of the saw-cut. The speckle pattern scheme associated with acquiring VIC-3D data is visible in Figure 9. Note that the high-resolution VIC-3D system required a much finer speckle pattern, which appears as a gray shaded area in Figure 9a, in the vicinity of the saw-cut. 


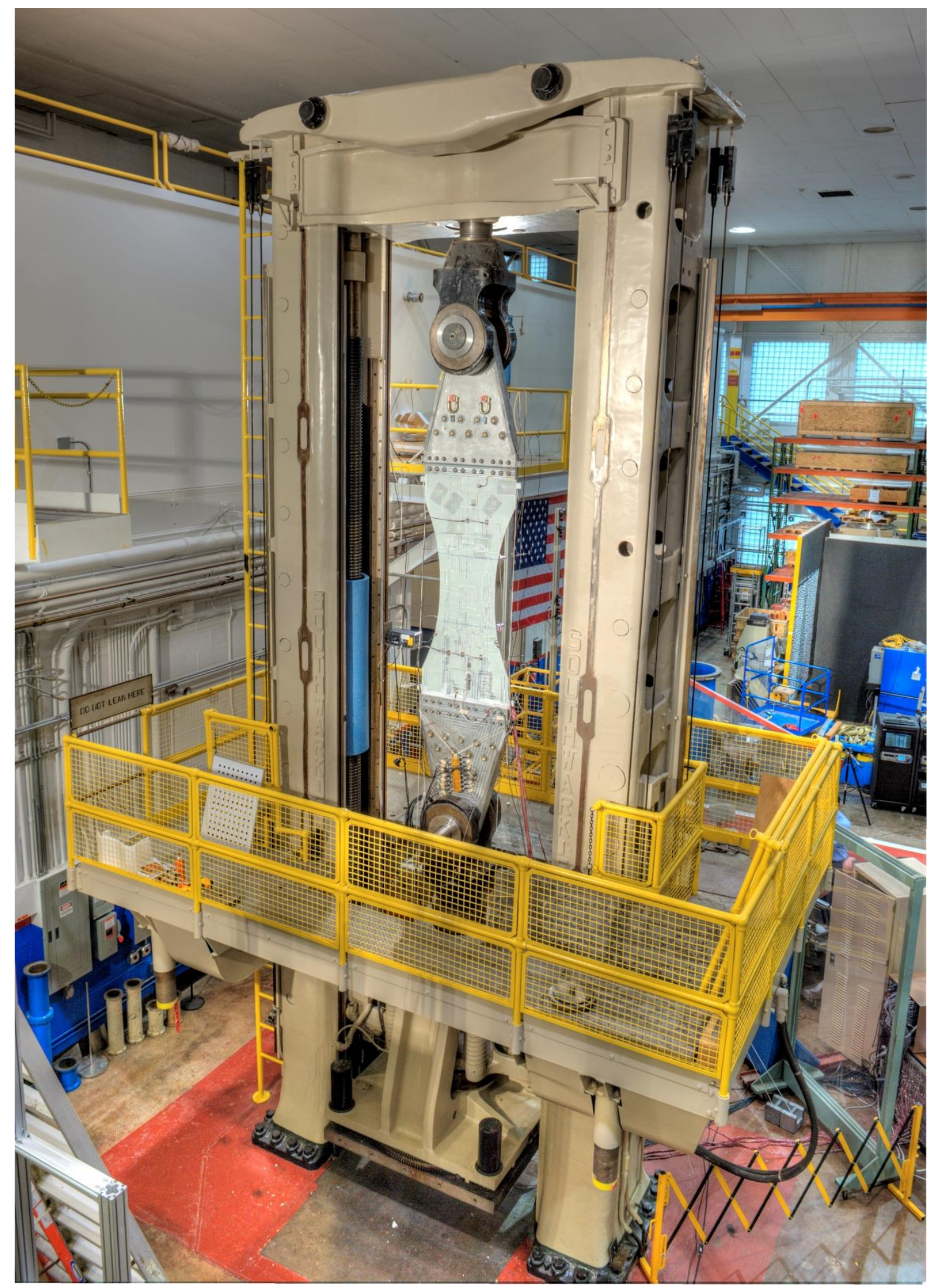

Figure 7. Repaired tension PRSEUS panel installed in the one million pound test machine at NASA LaRC.

8

American Institute of Aeronautics and Astronautics 
Strain gage, displacement, and load data were recorded in 0.1 second intervals while VIC-3D images were captured once every second. All three video recordings were normal speed, i.e., 30 frames per second. Two video recordings were made of the stiffened side of the panel. One stiffened-side recording captured almost the entire length of the specimen, including junctions of the panel with the load introduction lugs, while the other was focused on the center section of the panel, slightly larger than the section between the foam-filled frames. The unstiffenedside video recording captured approximately the dog bone section of the panel.

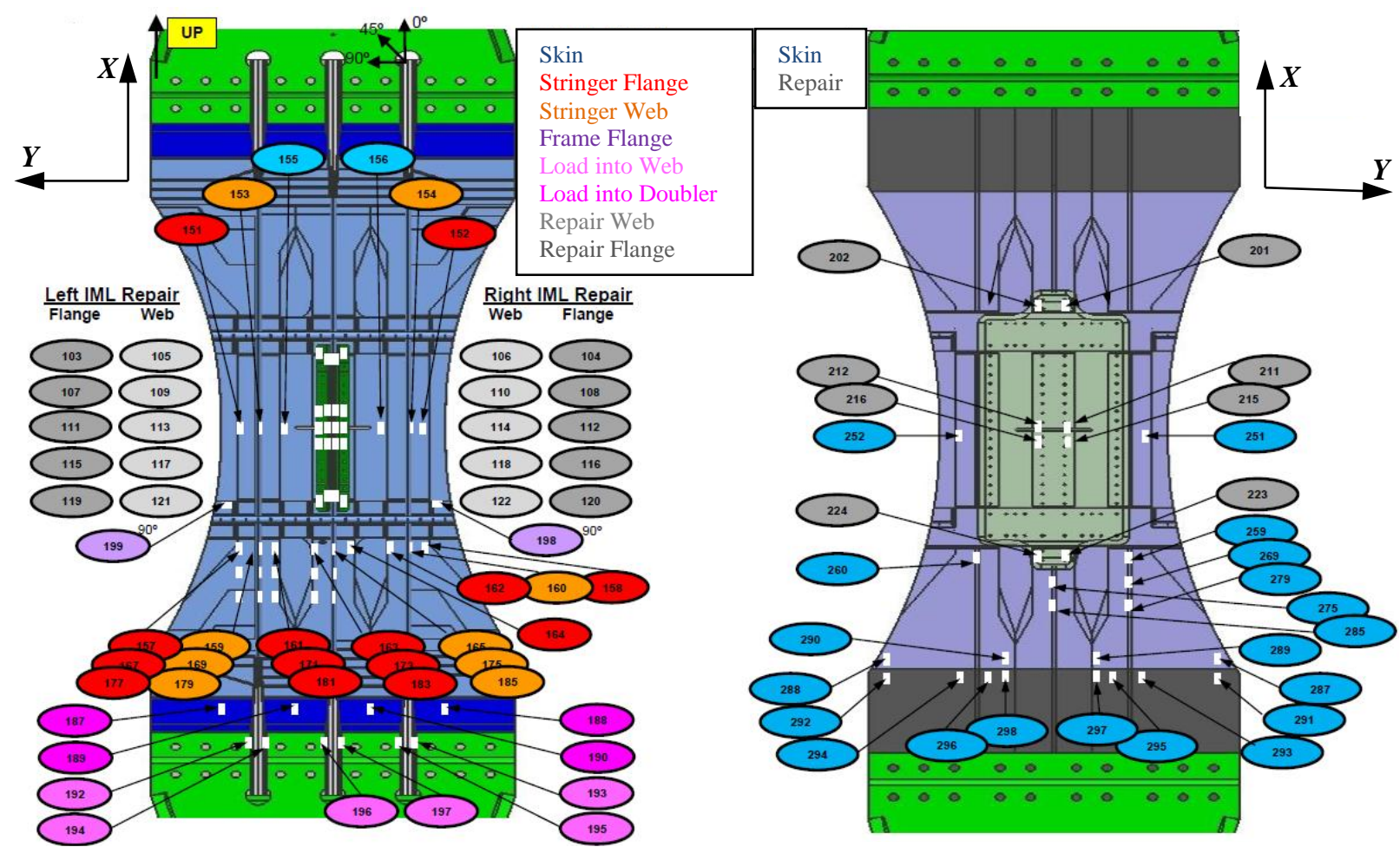

(a)

(b)

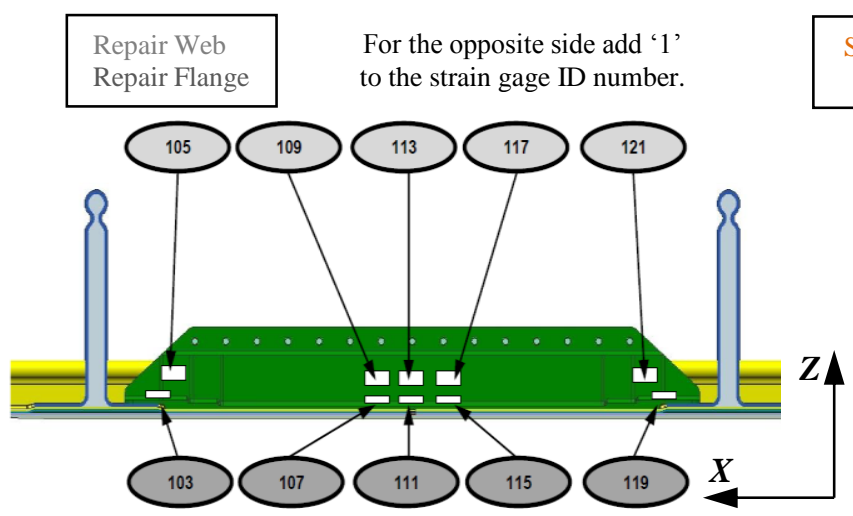

(c)

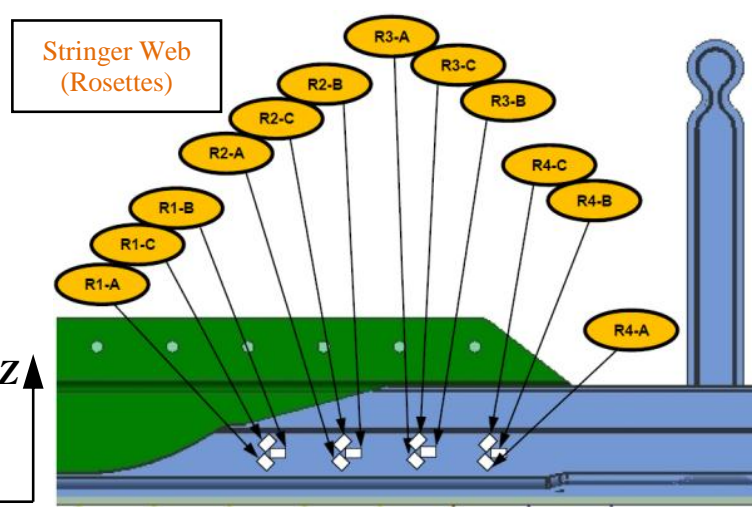

(d)

Figure 8. Strain gage locations on: (a) stiffened side, (b) smooth side, (c) stiffened side repair assembly and (d) tapered stringer under the stiffened side repair assembly. 


\section{Results and Discussion}

Experimental results including strain gage readings, displacement transducer results and full-field displacements acquired using the VIC-3D system are presented first in this section. A series of events occurred as load was slowly increased. A detailed discussion of the sequence of events leading to panel failure is divided into three load level regimes, i.e., less than DLL, between DLL and DUL, and greater than DUL until final failure. In addition, a separate section documents damage modes which did not become obvious until a post-test specimen examination when the repair assembly was removed from the panel. Next, comparisons between FE predictions and experimental results are shown. Finally the impact of these results on design allowables is discussed.

The final panel failure occurred at the loading of 243,992 lb. Failure mode is illustrated in Figure 9. The failure occurred away from the center section of the panel, i.e., away from the initial saw-cut damage, generally in the vicinity of the top foam-filled frame. While pin-to-pin elongation of the panel presented in Figure 10 shows linear global behavior up to approximately 213.5 kip load level, i.e., greater than DUL+10\%, subsequent sections detail several localized effects not identifiable in the global displacement plot. Some of these local events did not significantly influence the final failure, but nevertheless it is worthwhile to trace the damage progression, as it helps in understanding the mechanics of the structure. Identification of test behavior before embarking on FE predictions assessment is also helpful in the process as the adopted modeling assumptions and analysis fidelity can be placed in the context of the actual article behavior.

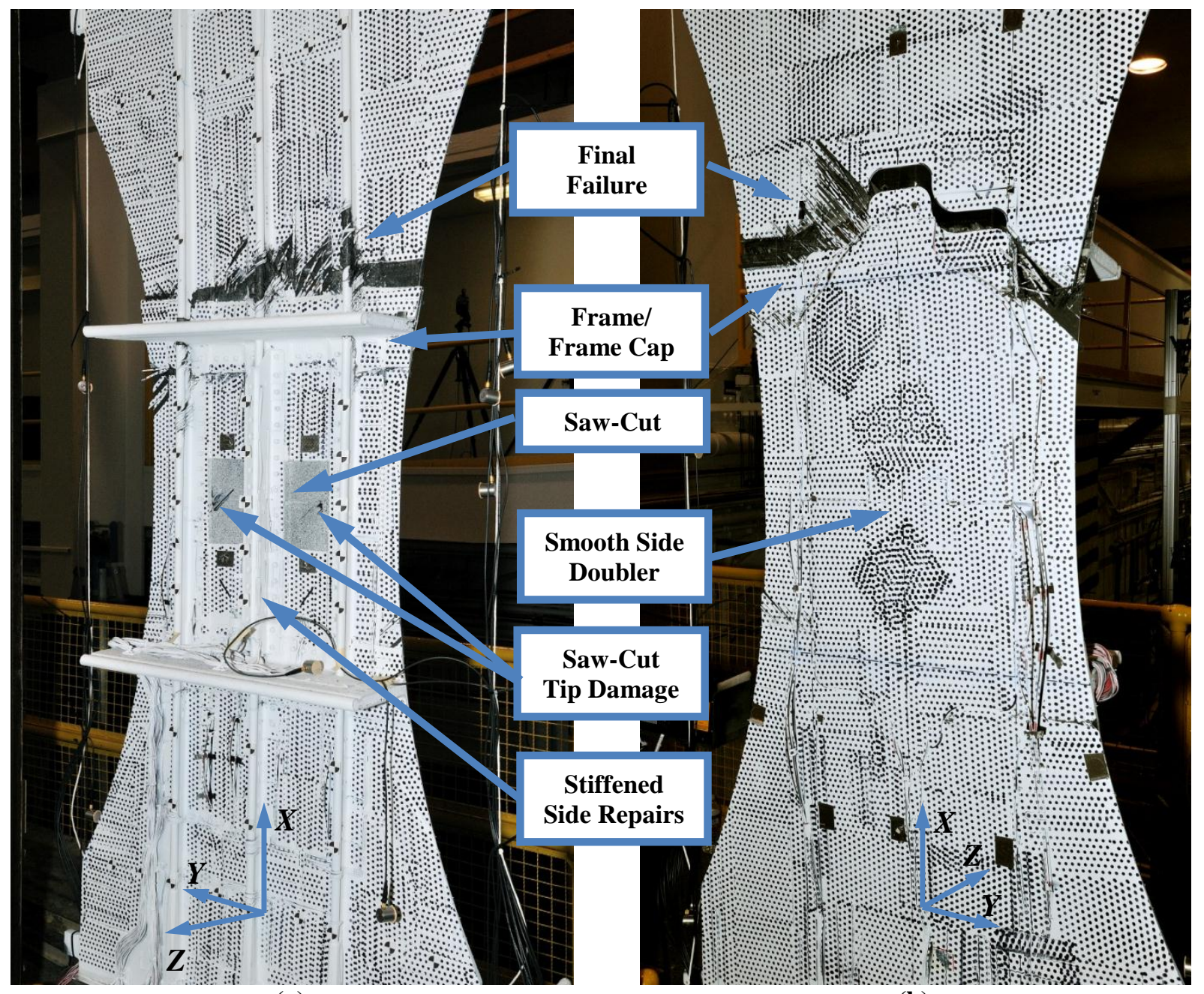

(a)

(b)

Figure 9. Failure of the repaired tension PRSEUS panel: (a) stiffened side, (b) smooth side. The speckle pattern applied for VIC-3D measurements is visible. 


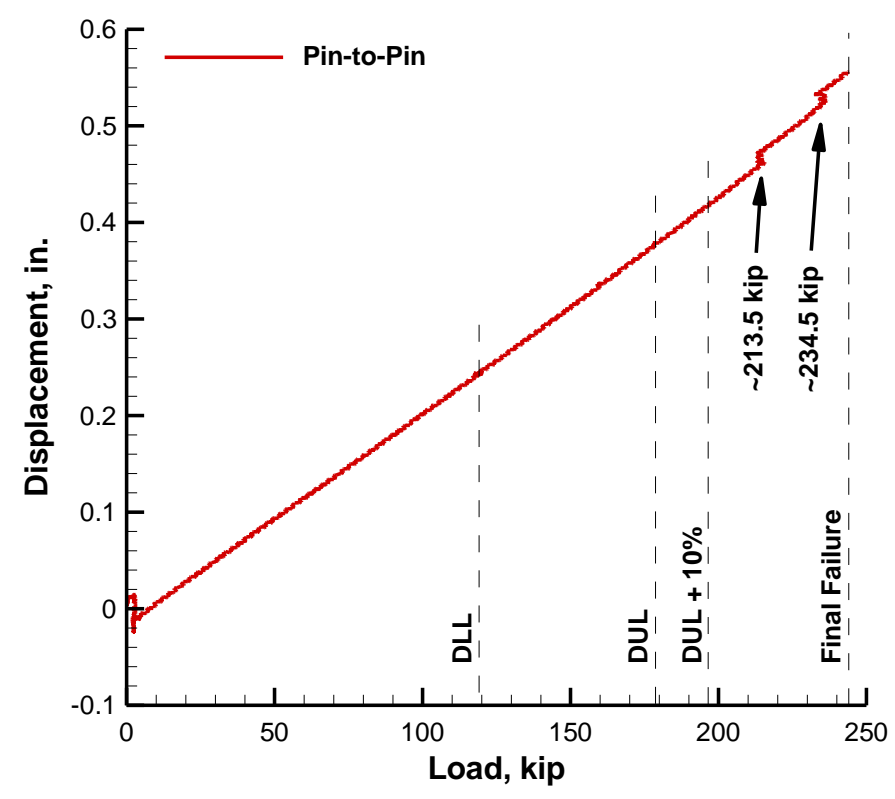

Figure 10. Pin-to-pin displacement versus loading.

\section{A. Panel behavior at load less than DLL}

The first identifiable local failure was initiated in the region of the right-hand-side saw-cut tip (when looking at the panel from its stiffened side) at a load of 102.5 kip or $86.1 \%$ of DLL and is shown in Figure 11. The tip of the saw-cut is highlighted with a yellow dashed line in Figure 11 and the speckling visible inside the saw-cut area is on the smooth side doubler. The surface fiber splitting is not easily visible in Figure 11, however, the extent of the splitting was $0.15 \mathrm{in}$. and was determined based on displacement contours from the high-resolution VIC-3D acquisition. Both left- and right-hand-side saw-cut tip openings and surface splitting lengths were traced using the high-resolution VIC-3D acquisition throughout the entire loading sequence. For brevity, only the surface openings are presented in Figure 12 along with strain readings from the two closest strain gages, SG-155 and -156, located one inch to the side of the left- and right-hand side saw-cut tips, respectively. It is seen in Figure 12 that the initial saw-cut tip event at 102.5 kip was so minor that it did not result in a noticeable strain reading disruption in the two aforementioned strain gages. It is therefore concluded that this local event did not significantly affect the behavior of the panel away from the saw-cut for load less than DLL.

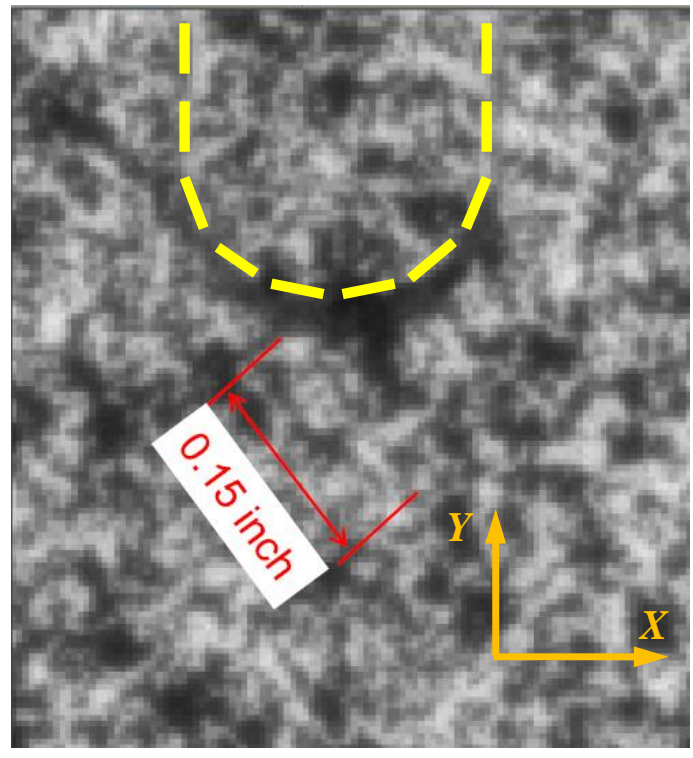

Figure 11. Initial surface opening at the right saw-cut tip at 102.5 kip.

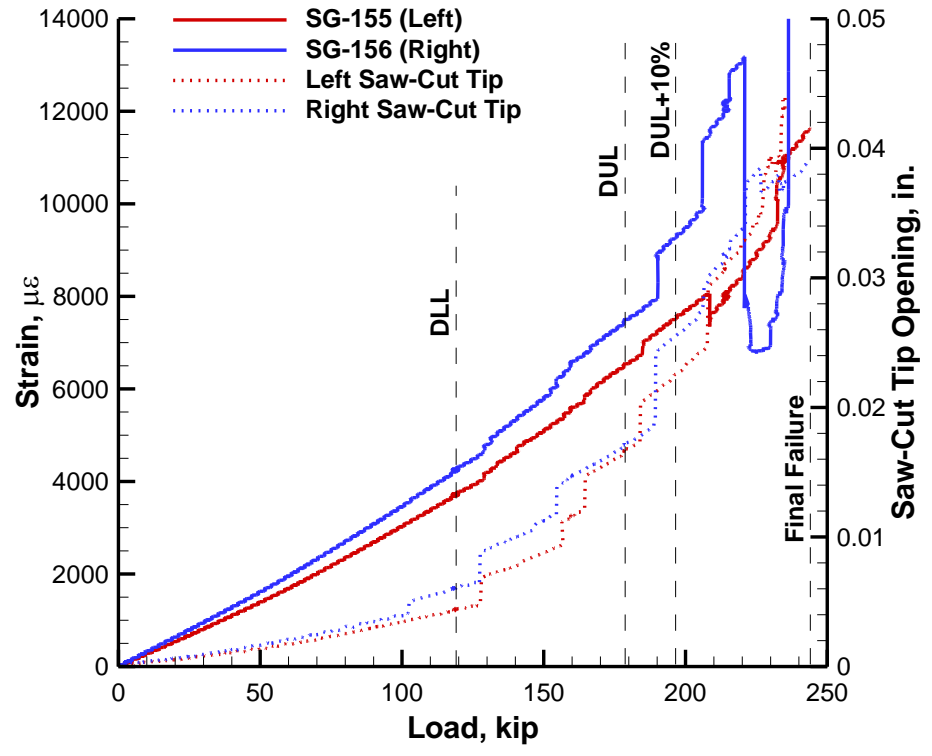

Figure 12. Saw-cut tip openings and strains in its vicinity.

11

American Institute of Aeronautics and Astronautics 
The only other minor event at load less than DLL was identified based on the strain gage data from the rosettes affixed to the severed stringer under the repair angles. Specifically, a slight discontinuity was first noticed in the strain principal direction shown in Figure 13 at 106.0 kip in rosettes SG-R1 and -R2. Note that these two rosettes are affixed to the tapered section of the stringer, where the pultruded rod has only a partial overwrap, a configuration that can potentially be prone to delamination. It is therefore concluded that a minor delamination in the tapered section between the pultruded rod and the partial overwrap might have occurred at this instance. Note that the event is so minor that the maximum principal strain values shown in Figure 14 are virtually unaffected.

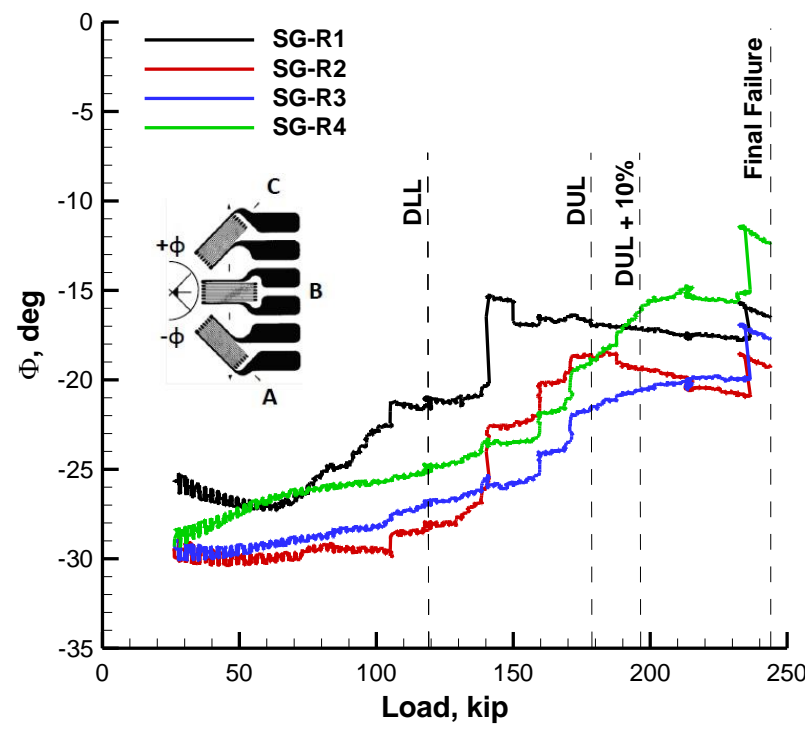

Figure 13. Principal strain direction from severed stringer strain gage rosettes.

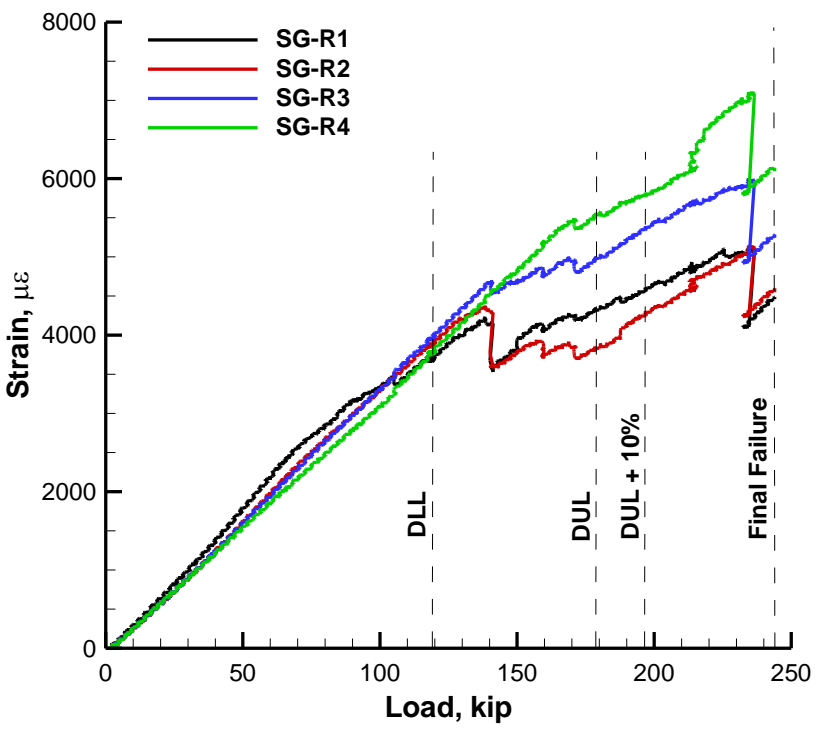

Figure 14. Maximum principal strain from severed stringer strain gage rosettes.

\section{B. Panel behavior for loads between DLL and DUL}

As the load was increased above the DLL, additional damage developed in the panel. Based on previously introduced principal direction and maximum principal strain plots (Figure 13 and Figure 14, respectively) it is likely that the suspected delamination of the pultruded rod in the severed stringer progressed in an abrupt fashion around $141.3 \mathrm{kip}$ load. This event was more pronounced when compared to the previously noted event of similar nature at 106.0 kip, as evidenced not only by a more substantial principal direction change in Figure 13 but also by a strain level reduction in Figure 14. Note though, that the behavior was still limited to SG-R1 and -R2 affixed within the tapered section of the severed stringer. Several less pronounced events occurred between 141.3 kip and DUL. While these discontinuities in principal strain direction and magnitude were considerably smaller, their significance stems from the fact that they involved a larger span of the severed stringer. This conclusion is based on discontinuities identified also for rosettes SG-R3 and -R4 affixed beyond the tapered section of the stringer.

Increasing tip opening and surface splitting lengths were also noticed near the saw-cut and, contrary to previous observation at load less than DLL, the surface splitting development was observed at both left- and right-side saw-cut tips. As this form of damage progressed, its effects became noticeable further away from the saw-cut tips, as strain gage SG-155 and -156 recorded some perturbations visible in Figure 12. Though the surface splitting length growth is not plotted for brevity, a gradual increase in saw-cut tip opening that did not correspond to the surface splitting length growth was observed. On the other hand, each discontinuity in a saw-cut tip opening shown in Figure 12 corresponded to an instantaneous increase in the length of the surface splitting. It was, therefore, concluded that gradual increases in saw-cut tip openings were associated with potential energy increasing at the saw-cut tip. The energy was released in an abrupt fashion when the length of surface splitting increased. Again, note that none of the events occurring at loads less than DUL lead to identifiable events in the global behavior, i.e., the pin-to-pin elongation versus load curve, as shown in Figure 10. 


\section{Panel behavior for load greater than DUL through final failure}

Further growth of surface splitting originating from the saw-cut tips was observed at loading greater than DUL. The two events presented below are distinct from the ones observed at the lower load regimes in the sense that the surface splitting reached the stitch lines, as shown in Figure 2, which prevented their further length growth. Despite the fact that only raw VIC-3D images are presented below in Figure 15 and Figure 16, the splitting and damage arrestment assessment was supported also by reviewing post-processed displacement contours. The damage arrestment occurred first on the right-side of the panel at 189.5 kip, an event visible in Figure 12 between the DUL and DUL $+10 \%$ lines. Examination of a high-resolution VIC-3D image acquired at this load and shown in Figure 16 revealed that this event was associated with the previously existing splitting extending further in the diagonal direction (i.e. along the red dashed line) from the saw-cut tip (the right end of the yellow dashed contour) to the flange edge of the right-most stringer (marked with the orange dashed line). A similar event followed on the left-side of the panel at 208.0 kip and is also visible in Figure 12 for loading slightly greater than DUL+10\%. The associated VIC-3D image is shown in Figure 15, with the same type of markings as in Figure 16. A slightly different surface splitting path is seen in Figure 15. After the initial growth in the diagonal direction for about 2/3 of the distance between the saw-cut tip and the left-most stringer flange, the surface splitting turned to the direction perpendicular to the stringers before being arrested at the flange edge. Note, that the single stack skin where the splitting developed was oriented perpendicular to the stringers. Therefore, the percentage of diagonal fibers was 42.9 and the percentage of fibers perpendicular to the stringers was 44.9 and these two directions dominated splitting development paths. Note also that in the global sense, the two events were still contained within the load range that did not produce any visible departure from a linear relation between the load and extensional displacement, as seen in Figure 10.

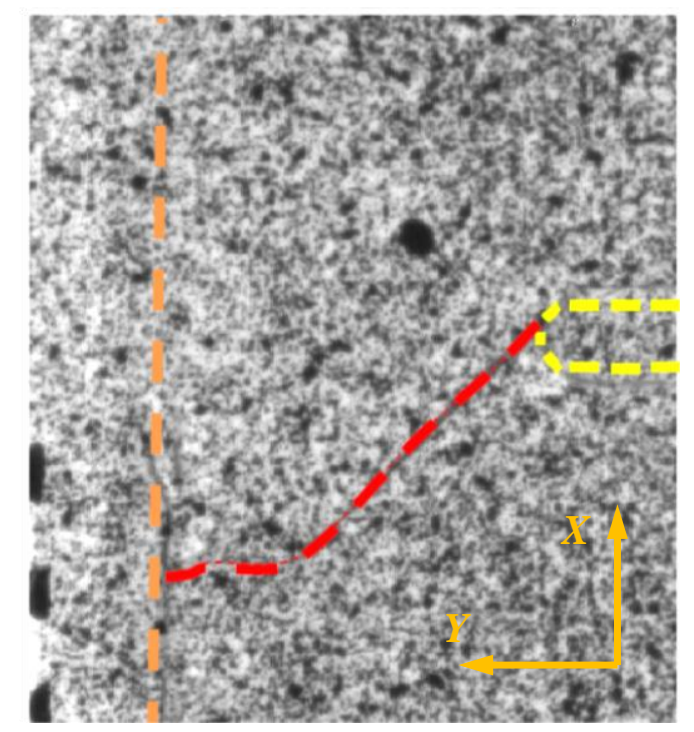

Figure 15. Saw-cut tip surface splitting arrested by the left-side stringer flange at 208.0 kip.

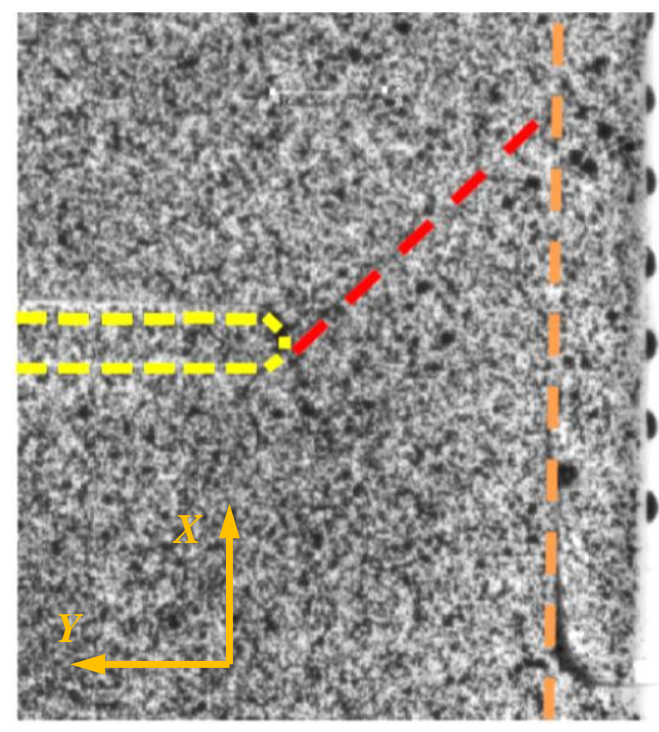

Figure 16. Saw-cut tip surface splitting arrested by the right-side stringer flange at $\mathbf{1 8 9 . 5}$ kip.

The final failure was preceded by two noticeable load reductions, as illustrated in Figure 10, occurring around 213.5 kip and 234.5 kip. More detailed examination of the two load reductions in Figure 10 (not shown for brevity) revealed that each were comprised of two separate but closely spaced events. A summary of the loads and locations of these events is shown in Table 2. 
Table 2. Summary of events associated with the two load reductions.

\begin{tabular}{|c|c|c|c|c|}
\hline \multirow[t]{2}{*}{ Event } & \multicolumn{2}{|c|}{ Load, kip } & \multirow[t]{2}{*}{ Description } & $\because \cdots \cdots \cdots$ \\
\hline & Before & After & & \\
\hline$\left(1^{\text {st }}\right.$ event in the $1^{\text {st }}$ load reduction $)$ & 214.5 & 212.7 & $\begin{array}{c}\text { Cracks } \\
\text { developed in area A }\end{array}$ & \\
\hline $\begin{array}{c}2 \\
\left(2^{\text {nd }} \text { event in the } 1^{\text {st }} \text { load reduction }\right)\end{array}$ & 214.2 & 212.9 & $\begin{array}{c}\text { Cracks } \\
\text { developed in area B }\end{array}$ & \\
\hline$\left(1^{\text {st }}\right.$ event in the $2^{\text {nd }}$ load reduction $)$ & 234.5 & $234.5^{(*)}$ & $\begin{array}{l}\text { Additional cracks } \\
\text { developed in area } \mathrm{A}\end{array}$ & \\
\hline$\left(2^{\text {nd }}\right.$ event in the $2^{\text {nd }}$ load reduction $)$ & 235.6 & 233.1 & $\begin{array}{l}\text { Event suspected in the } \\
\text { center stringer in area } C\end{array}$ & \\
\hline
\end{tabular}

${ }^{(*)}$ Loads associated with the VIC-3D data acquisition shown above are sampled at 1 second rate. Loads associated with the strain gage data sampled at 0.1 second rate confirmed initial load increase and subsequent reduction.

Video recordings and VIC-3D images indicated that prior to the final failure, damage was gradually introduced from the lateral free edges of the panel in the vicinity of the frame caps. Since the first three out of four abovementioned events were very similar in nature, only the third one (i.e. the first event in the second load reduction at $234.5 \mathrm{kip}$ ) is illustrated in Figure 17. Figure 17 comprises of the VIC-3D out-of-plane displacement plots presented along with close-up images of the section of the panel where the damage was introduced. Two consecutive frames captured by the VIC-3D system in one second interval are presented. The two top images show the pre-existing damage that occurred at the $213.5 \mathrm{kip}$ load (the aforementioned first event associated with the first load reduction) and did not progress any further up to the load of 234.5 kip. It is seen that the initial cracks in the skin section of the panel developed at the 45-degree angle and arrested in the vicinity of the top frame cap and the right-hand-side stringer flange intersection, where the through-the-thickness stitching is present. The bottom images in Figure 17 show additional damage in the form of a new distinct 45-degree crack highlighted with a red arrow in the VIC-3D image. Local change in the out-of-plane displacement is also visible in the area highlighted in the left plot. Recall that the panel frame caps were four stacks thick $(0.208 \mathrm{in}$.) and their intersections with stringer flanges were six stacks thick (0.312 in.) while the skin was only one stack thick (0.052 in.). These abrupt changes in the panel thickness near the frame caps likely resulted in stress concentrations that contributed to damage initialization. Finally note that shortly after the first crack shown in the top images of Figure 17 developed, a second event (i.e., the second event very similar in nature to the first in the first load reduction) occurred on the opposite side of the panel near the bottom frame. The damage was nearly identical to the one shown in the top section of Figure 17 and its presentation is omitted here for brevity. 

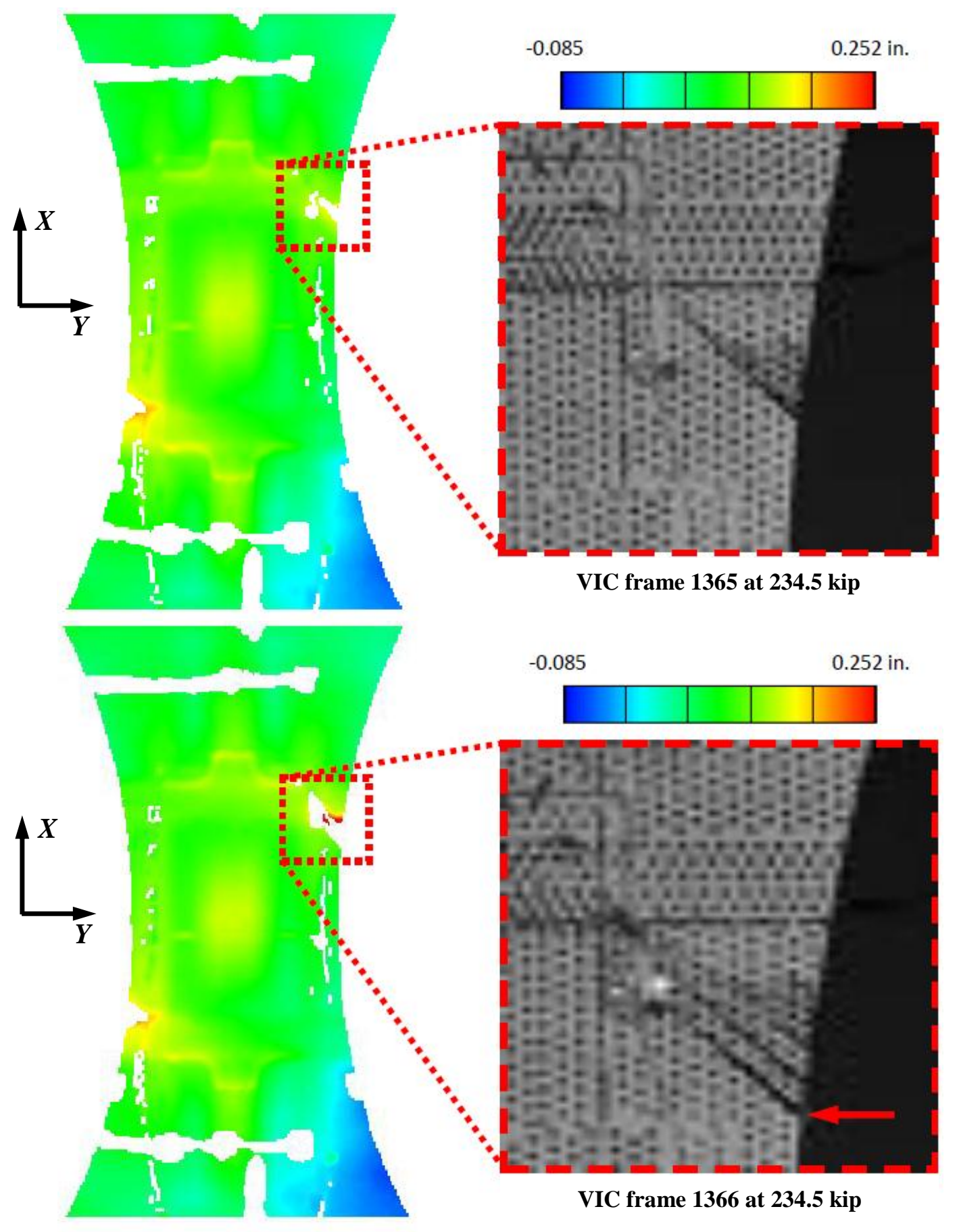

(a)

(b)

Figure 17. Edge failures as first event in the second load reduction: (a) out-of-plane displacement, (b) close-up image.

While the first three out of four previously mentioned events associated with the two load reductions in Figure 10 were similar in nature, the last event could not be traced to regions near the free lateral side edges of the panel. However, the event was also identified by examining the out-of-plane displacement fields acquired from the VIC-3D system. This change in displacement field is illustrated again with two consecutive frames in Figure 18. Sections of the panel where the change was most noticeable are enclosed within dashed contours. It is observed that the event had its predominant impact in the vicinity of the center severed stringer. 

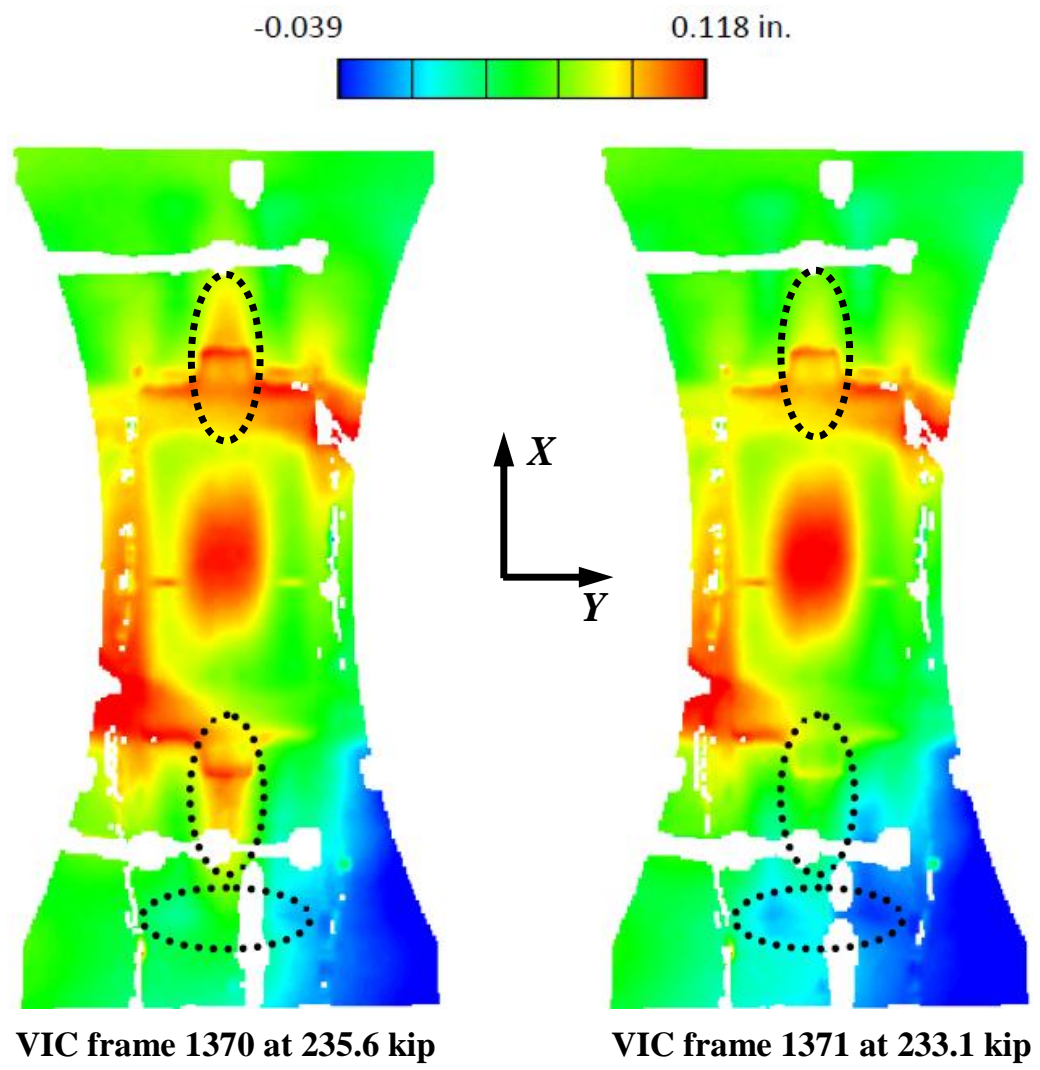

Figure 18. Second event of the second load reduction: out-of-plane displacement, regions of dominant displacement change highlighted with dashed contours.

Given the above observation, strains acquired from the four strain gage rosettes attached to the severed stringer web, as shown in Figure 8(d), were further examined. Principal directions and maximum principal strains obtained from the four rosettes were presented in Figure 13 and Figure 14, respectively and several discontinuities occurring at loads less than DUL were already discussed in sections V.A and V.B. Note that the first load reduction identified in Figure 10 at approximately 213.5 kip is not associated with an appreciable discontinuity in the severed stringer principal direction or the maximum principal strain. On the other hand, the second load reduction at approximately 234.5 kip is clearly associated with a large principal direction and principal strain discontinuities in all four rosettes. Post-failure examination results of the panel can be linked to this behavior and are discussed momentarily in the following section.

\section{Post-failure panel examination}

As indicated before, the final failure of the panel occurred in the vicinity of the top foam-filled frame away from the repaired saw-cut area. The final failure mode was presented in Figure 9. The panel and the repair components were disassembled after the test to allow examination for damage modes not visible in the assembled configuration and to correlate gage readings, especially their discontinuities, with a probable damage sequence scenario. The two general areas where additional examination was enabled by disassembling the repair were the center stringer and fastener holes.

Post-test examination after removing the repair assembly revealed that the upper section (as installed in the test machine) of the severed pultruded rod was delaminated from its overwrap beginning in the tapered section of the web, as shown in Figure 19(a). No visible rod delamination was identified in the lower section of the stringer, as shown in Figure 19(b). Recall from Figure 8(d) that the upper stringer section was not instrumented under the repair assembly but the lower section had four strain gage rosettes installed in the web section of the stringer. Recall also, that when discussing discontinuities in the principal strain direction and the maximum principal strain (Figure 13 and Figure 14, respectively), a delamination of the pultruded rod was cited as their possible cause. The fact that a visible rod delamination occurred only in the stringer section that was not instrumented does not invalidate the previously provided explanation. Delamination of either of the rod sections, i.e., lower (instrumented) or upper (not 
instrumented) results in the same outcome, specifically, an abrupt stiffness change and a significant shift in the location of the neutral bending axis. This shift influences the out-of-plane displacement of the panel not only directly over the delaminated section but more globally, which is consistent with the behavior shown in Figure 18 . It is therefore probable, that the extensive delamination of the pultruded rod from the overwrap occurred as the second event in the second load reduction shown in Figure 10, after which the panel was still capable of sustaining additional load before the final failure.

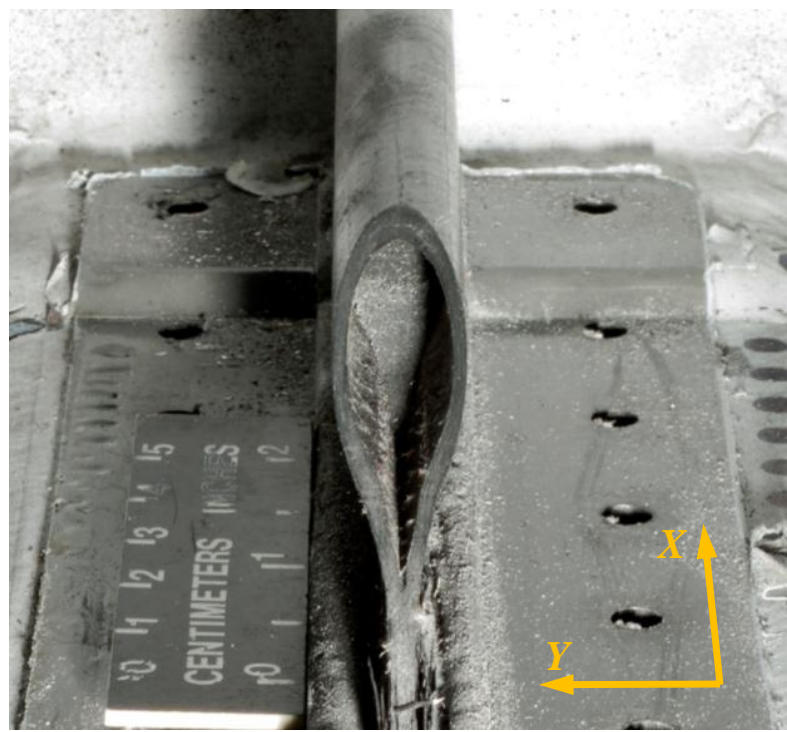

(a)

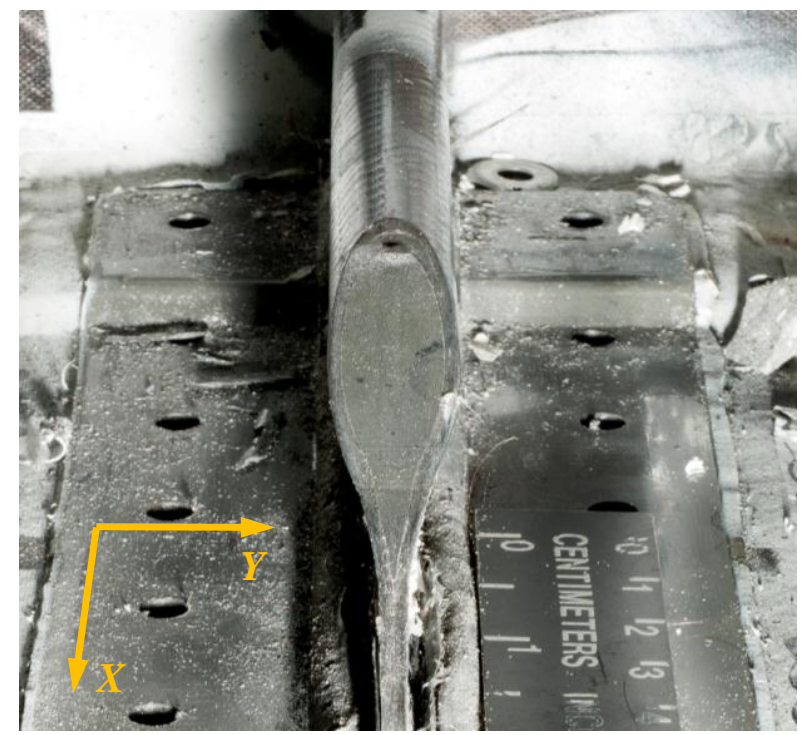

(b)

Figure 19. Tapered section of the center stringer: (a) pultruded rod delaminated and partially pulled out of overwrap in upper taper, (b) pultruded rod and stringer overwrap not delaminated in lower taper.

Fastener joints were examined next. While the titanium fasteners were compromised during the disassembling process, examination of fastener holes yielded meaningful observations. No visible elongations of fastener holes were observed in the composite panel, as shown in Figure 20 for highly-loaded fastener holes in the direct vicinity of the saw-cut. In the same figure it is also seen that extensive surface splitting in the saw-cut area developed further beyond those previously shown in Figure 15 and Figure 16. Despite the much larger extent, splitting propagation was also arrested by the through-the-thickness stitching reinforcement at the side flanges.

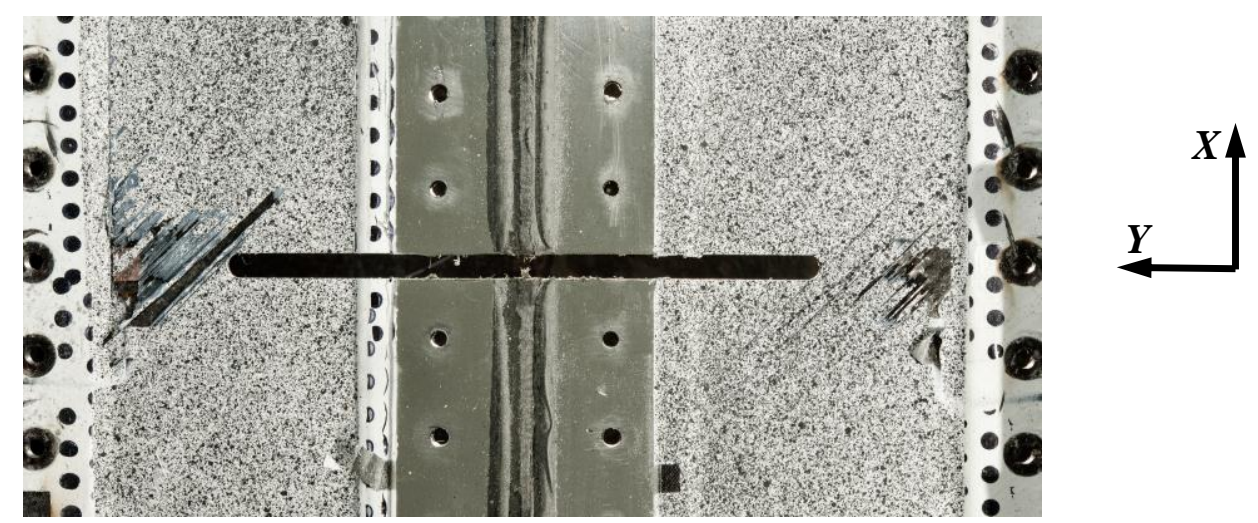

Figure 20. Fastener holes in the center stringer of the panel in the vicinity of the saw cut.

Fastener holes in the composite panel showed no signs of damage while some highly-loaded holes in the metallic components of the repair assembly revealed elongations as shown in Figure 21(a) for the doubler and in Figure 21(b) for the two repair angles. The above behavior was predicted by a supplemental hand calculations to be discussed at the end of section V.E. Close-up sections in Figure 21 show the eight fastener holes corresponding to the fastener holes in the center section of Figure 20 near the saw-cut. A careful examination of the metallic repair assembly components clearly shows the elongations but they are difficult to see in photographs. While the exact 
elongations in the metallic repair components were not measured, their presence was verified by inserting pristine fasteners into the holes while orienting them vertically. The holes which did not elongate during the test would not permit fasteners sliding freely due to tight initial tolerances being maintained. Elongated holes were not able to sustain fasteners as they would easily slide out from the holes under their own weight. Note that the close-up areas in Figure 21 are only selected examples and do not show all the elongated fastener holes. Additional elongated fastener holes were identified at the end sections of the doubler and the two angles.

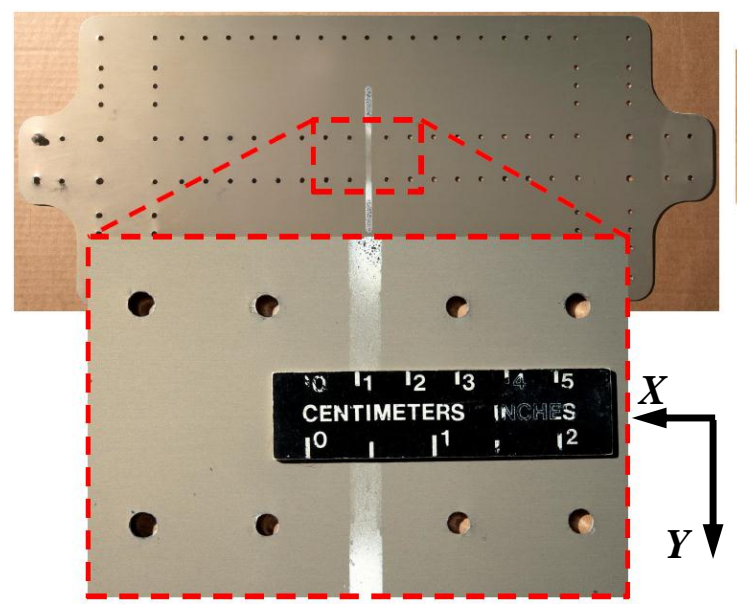

(a)

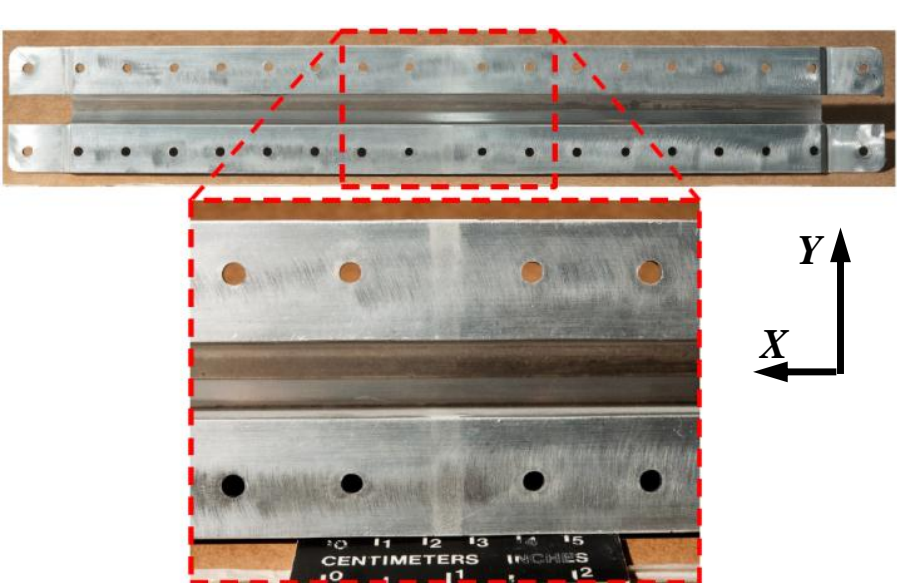

(b)

Figure 21. Elongated fastener holes in the repair assembly: (a) smooth side doubler and (b) stiffened side angles.

Finally, one more isolated example of a damage mode was noticed when examining fastener holes. Namely, a crack in the top left fastener hole propagated to the end of the angle is shown in Figure 22. The crack occurred on the side of the fastener hole closer to the fillet between the web and flange section of the angle, i.e., closer to a more rigid angle section due to the fillet thickness build up. To identify a possible load at which this event occurred, the closest strain gage SG-103 recording was examined and compared to the other three similarly placed strain gages SG-104 (top right), -119 (bottom left) and -120 (bottom right). Figure 22 shows that SG-103 recorded a small discontinuity at 227.9 kip which was not identified in the other three gages at this load level. Therefore, it is likely that the fastener hole crack developed gradually over lower load levels and reached the free edge of the angle at 227.9 kip.

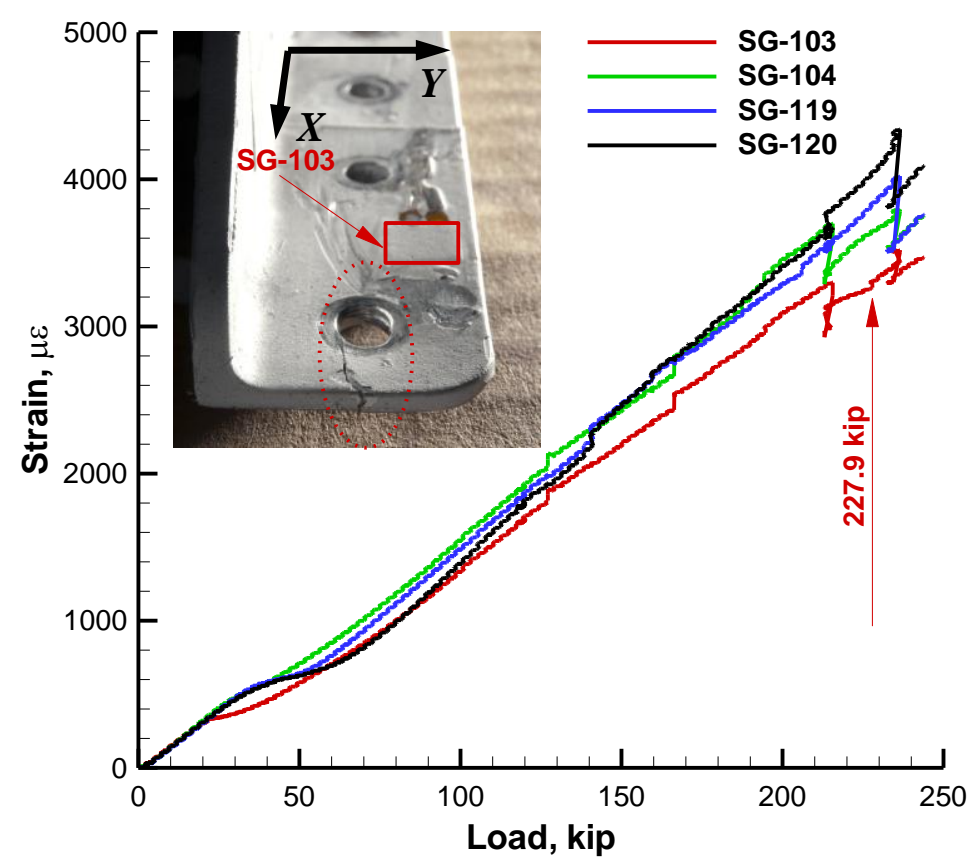

Figure 22. Crack at the top fastener hole of the left repair angle and pertinent strain gage data.

18

American Institute of Aeronautics and Astronautics 


\section{E. Correlation of test results with finite element analysis}

Previous sections describing panel behavior leading to its final failure presented several events that the fidelity of the FE analysis used in the repair design effort did not support, such as surface splitting, crack growth or delamination. Nevertheless, within the load range up to DUL+10\% over which the FE analysis was performed, these events had very localized effects. This section focuses on assessing the quality of the FE analysis in a global perspective. Note that significant portion of the critical assessment of the analysis is deferred until the end of this section, when several factors relevant to the discussion are all introduced.

First, full field experimental displacement fields were compared with the FE analysis results to verify that the overall behavior of the test panel resembled that obtained from the predictions. Due to the smoothness of the unstiffened side of the panel, global VIC-3D system produced larger and less fragmented acquisition on this side of the panel. The extensional displacement field for the smooth-side doubler is shown in Figure 23 and compared with the FE prediction. For brevity, only the results for DUL of 178.7 kip are presented. Overall, a good agreement is demonstrated by similar displacement patterns and comparable displacement magnitudes. Nevertheless, the test data shows some distortions to the displacement field symmetry and generally displays a smaller extension of the doubler.

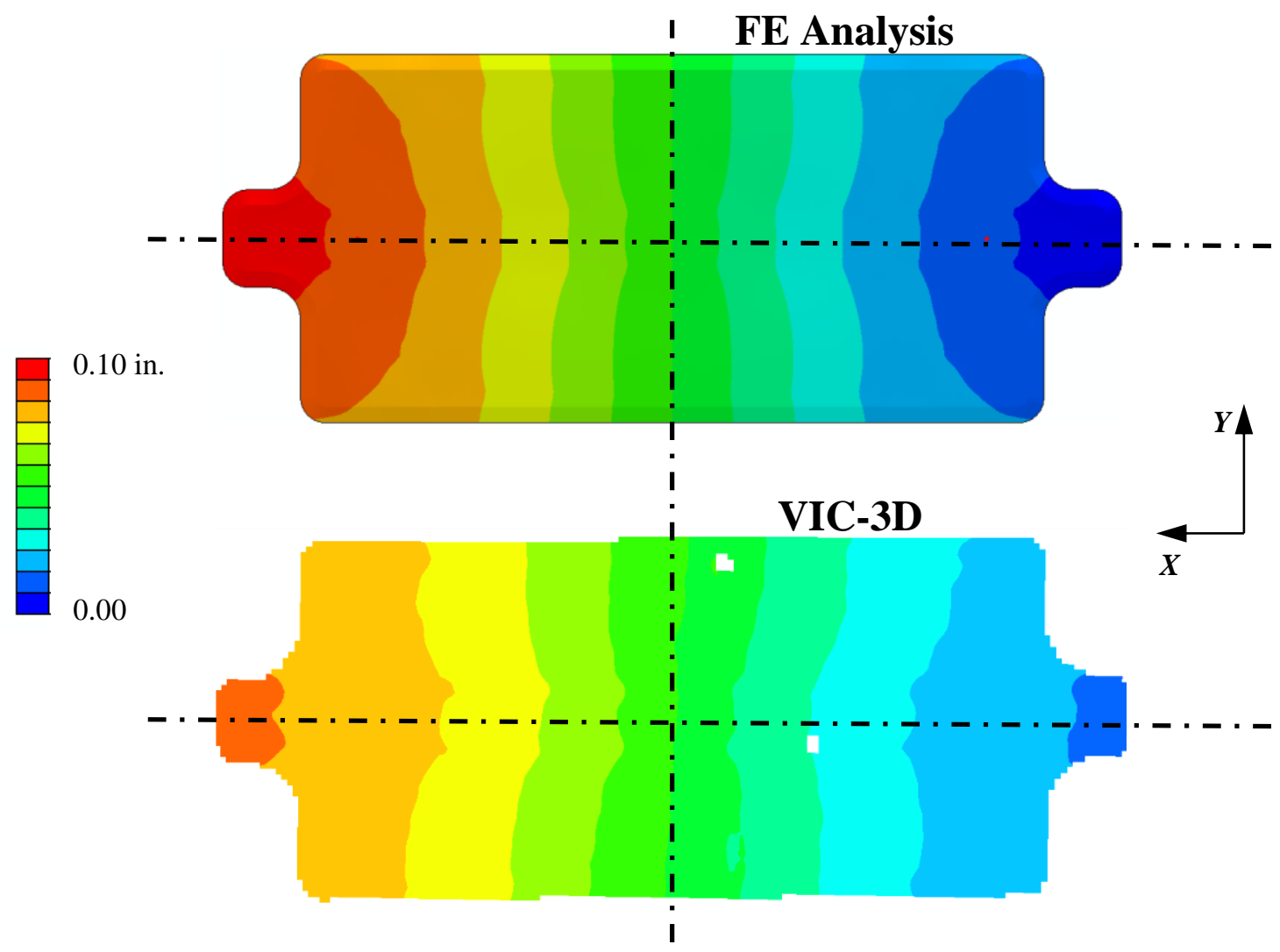

Figure 23. In-plane extensional displacement of the smooth side doubler at the DUL of $178.7 \mathrm{kip}$.

Comparison of the strain results at the mid-span station of the repair panel, i.e., in the vicinity of the saw-cut where high strain levels were anticipated,${ }^{11}$ is presented next. Strain levels in both metallic repair components and undamaged sections of the panel are compared for completeness. Specifically, mid-span strain results obtained on the stiffened side of the panel are compared in Figure 24 and Figure 25 for the two outside stringers. Flange results are shown in Figure 24 and web results are shown in Figure 25. Strain results obtained on the stiffened side repair assembly are compared in Figure 26 and Figure 27 for the flange and web sections of the repair angles, respectively. Finally, strain levels on the smooth side of the panel and the smooth side doubler are compared in Figure 28 and Figure 29, respectively. Note, that while the FE analysis yielded symmetric strain fields, some of the measured strain levels departed slightly from the symmetric distribution, as implied by displacement results presented in Figure 23. Therefore, Figure 24 through Figure 29 always present two strain curves obtained from a pair of 
symmetrically placed strain gages, while only one set of points is presented for the FE analysis results. The three load levels for which the FE results are presented are DLL, DUL and DUL+10\%, as discussed in section II.D. The strain acquisitions up to the final failure load are presented for the test data with solid lines. When FE analysis results depart significantly from the test data, dashed lines are introduced between the points corresponding to the FE analysis results to better highlight diverging trends. All strain gage locations are shown in Figure 8.

The FE analysis results compare very favorably with the test strain levels in the flanges of the two outside stringers, as shown in Figure 24. While the test data shows slight non-symmetry, the FE analysis results are enveloped by the test results from the two symmetrically placed sensors. Test strain levels in the webs of the two outside stringers, presented in Figure 25, show almost identical values for both sides of the panel and also compare very well with the FE analysis results, where the latter show a slight tendency to overestimate the actual strain levels. This tendency may be introduced by a simplified FE modeling of the stringers ${ }^{10,11}$ where the pultruded rod and overwrap are modeled together as beam elements and, therefore, the rod overwrap is not explicitly modeled.

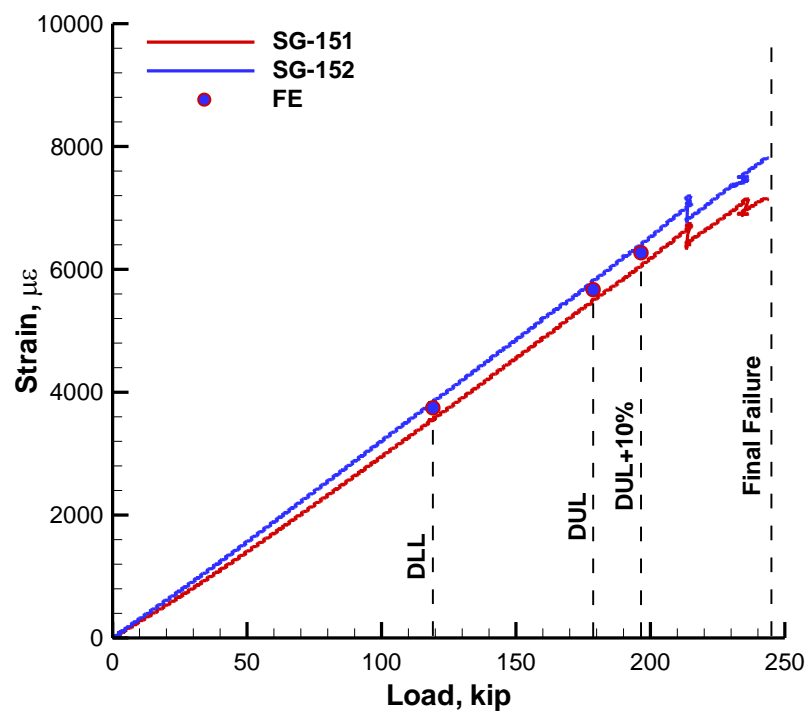

Figure 24. Mid-span strain vs. load at the flanges of the outside stringers.

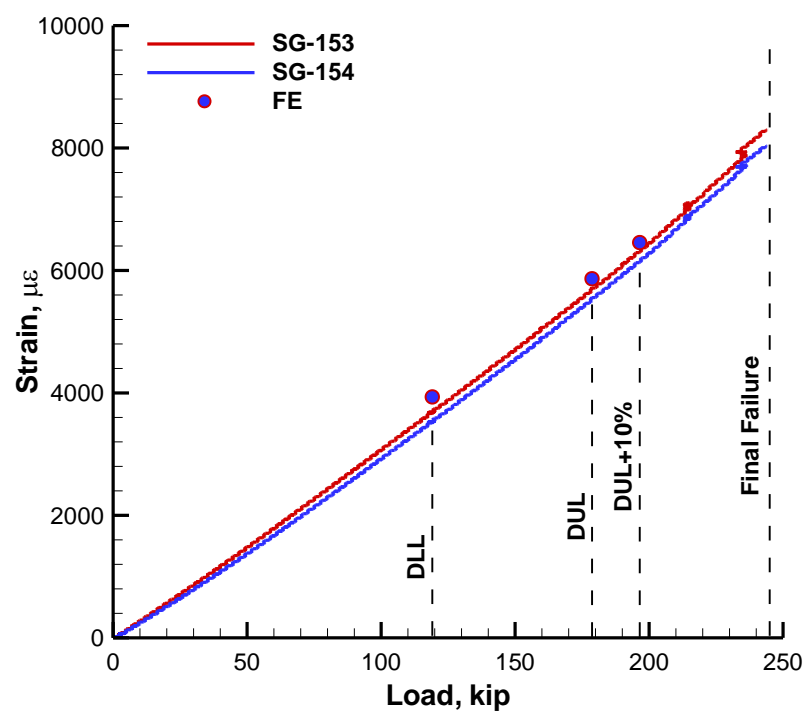

Figure 25. Mid-span strain vs. load at the webs of the outside stringers.

The strain level comparison at the flange section of the stiffened side repair, presented in Figure 26, shows a good comparison only up to the load of approximately $140 \mathrm{kip}$, which is greater than DLL but less than DUL. Even though the comparison for load less than 140 kip is considered good, a slight departure from the linear characteristic is noted in the test results, but absent in the FE analysis results. For load levels greater than approximately 140 kip the test strain values tend to asymptote and reach only approximately $5,500 \mu \varepsilon$ level at the failure load. The FE analysis results for loads greater than $140 \mathrm{kip}$, however, first show a linear strain characteristic up to approximately the DUL of 178.7 kip, followed by a softening characteristic due to the yielding stress being exceeded and the plastic response regime being introduced in the mid-span repair section. ${ }^{11}$ To assist in analysis of this discrepancy the strains acquired in the web sections of the repair angles are presented in Figure 27, where a less-pronounced but similar softening response for the load greater than DUL can also be noticed and is accurately captured by the FE analysis. ${ }^{11}$ Since the locations corresponding to the results in Figure 26 and Figure 27 are only approximately 1.175 in. apart, the difference in strain characteristics may appear surprising at first. Since the flange section of the stiffened side repair is bolted to the panel but its web section is not bolted to the panel, the discrepancy between the measured and predicted strains can be assumed to be related to the manner in which the load is transferred from the damaged center stringer of the panel into the repair assembly. However, strains on the smooth side of the panel must be considered to develop a more complete picture of the test versus analysis comparison. 


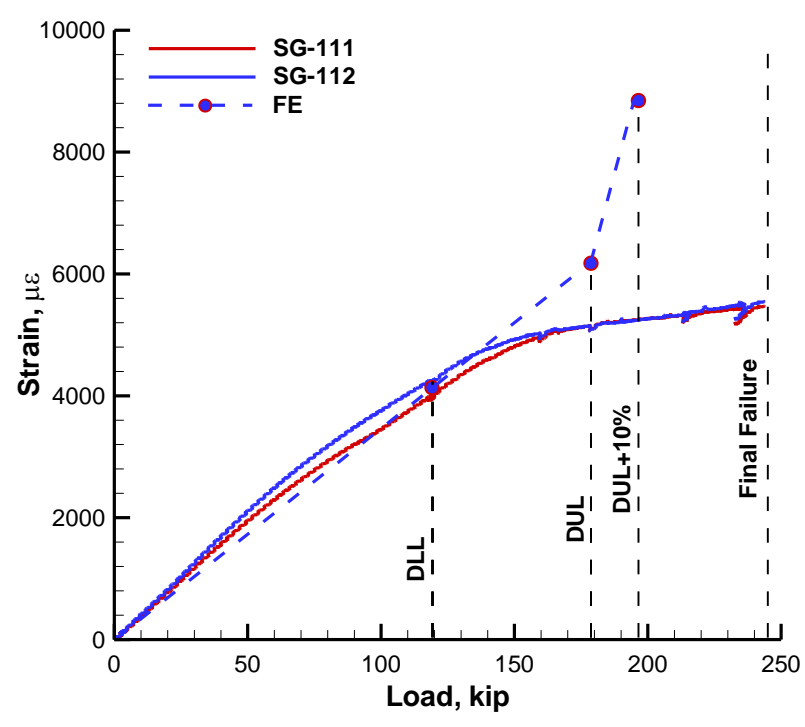

Figure 26. Mid-span strain vs. load at the flange section of the repair.

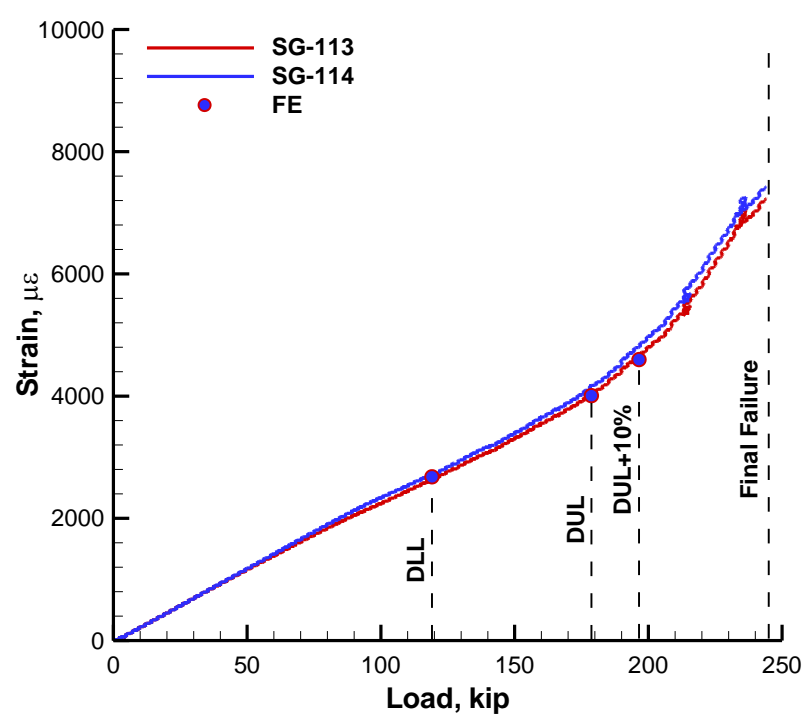

Figure 27. Mid-span strain vs. load at the web section of the repair.

Results for strain gages which are back-to-back relative to those of Figure 24 are shown in Figure 28 . The quality of strain comparison on the smooth side of the panel presented in Figure 28 is very good and matches the quality of comparisons achieved in Figure 24 and Figure 25. Strains measured at the mid-span of the smooth side doubler are presented in Figure 29 and match the FE analysis results well only up to approximately 70 kip, i.e., half of the load level up to which a good comparison was obtained on the flange section of the stiffened side repair, as presented in Figure 26. Furthermore, the first noticeable departure from the linear behavior occurred at a very low load level of approximately $30 \mathrm{kip}$, which might be indicative of fastener joints slipping, especially given that the doubler had countersinks. The second even less pronounced bend in the strain curves occurred around 150 kip, a level comparable to a similar behavior observed in Figure 26. In this context, note that locations of strain gages SG111 and -112 in Figure 26 are back-to-back relative to strain gages SG-211 and -212, respectively, in Figure 29. Also note that, per Figure 4(a), 36 fasteners installed in the center stringer flange are double shear fasteners that attach both smooth side doubler and stiffened side repair components to the severed stringer.

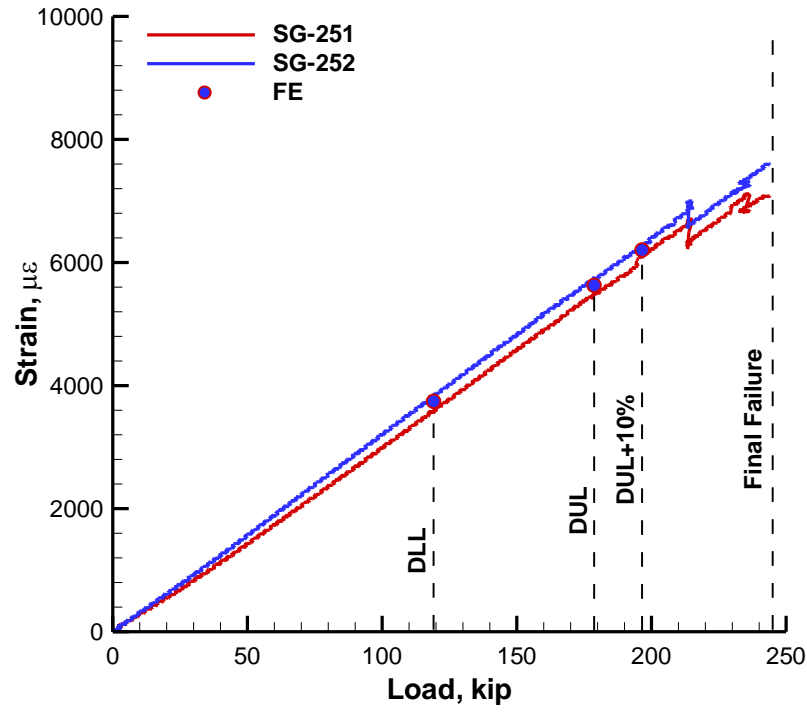

Figure 28. Mid-span strain vs. load on the smooth side of the panel opposite to the outside stringers.

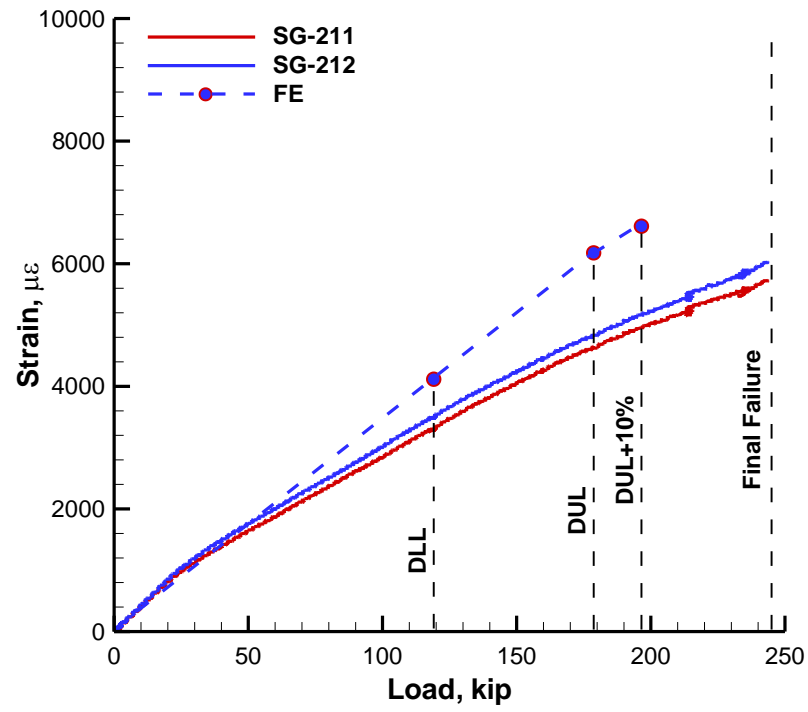

Figure 29. Mid-span strain vs. load on the smooth side repair doubler. 
Given the FE modeling techniques employed in the present FE analysis and outlined in section III, it is reasonable to expect that the behavior of the repair panel was more reliably predicted in its general far-field sections rather than in the vicinity of the fastener joints. Recall that modeling of fastener joints was considerably simplified as the fastener holes were not explicitly modeled and fasteners themselves were represented by connector elements. With such reduced level of fidelity, fasteners and their associated bearing surfaces in the fastener holes were not sufficiently represented to permit calculation of the bearing and bypass stresses within the FE analysis. Furthermore, while material properties of the composite panel can be assumed to be elastic in the entire regime prior to failure, metallic repair components yield before failure. Despite the fact that the elastic-plastic material properties were prescribed for the metallic repair assembly, yielding in the vicinity of the fastener joints could not be accurately predicted by the model. Hand calculations performed using fastener forces obtained from the FE analysis for loads greater than DLL, however, confirmed that a subset of the center flange fasteners would produce bearing stress levels exceeding the yielding stress on both stiffened side angles and smooth side doubler. Elongations of some fastener holes noted after the test and described in section V.D substantiate this result.

While accounting for the bearing stress exceeding the yielding value appears to be conceptually straight forward, its practical implementation within a commercial FE code can be cumbersome and/or may involve incurring a significant computational cost. One solution is to directly model each fastener hole and fastener. This approach would involve mesh refinements near the fastener holes, each fastener modeled with several solid elements, and multiple contact problems defined for all the hole-fastener pairs in the repair panel. All of the above means significantly increased model development and analysis times. On the other hand, when fastener holes are not modeled and fasteners are represented with connector elements, as in the present study, a considerable postprocessing of data needs to be carried out after each very small load increment before model adjustments, if warranted, are implemented and analysis can resume. Namely, after each integration step connector forces would need to be post-processed to produce bearing stress values, as such functionality is not available within the commercial FE code employed in the study. For the fastener locations where the yielding stress would be exceeded (this subset of locations would be constantly changing as the load level increases), the elastic material properties would need to be replaced with the plastic material properties. Furthermore, the spatial extent of the plastic region would also be difficult to assess given the absence of the actual drilled hole geometry and coarser elements in the vicinity of connector elements.

Generally, when the bearing stress value exceeds the yielding stress in a fastener hole, the spatial extent of the plastic region is very limited compared to the overall dimensions of the repair assembly. At the same time plastic modulus $H$ that is approximately 170 times smaller than the elastic modulus $E$ begins to govern the behavior of the aluminum part near this fastener (refer to 7075-T6 alloy data in Table 1). Therefore, the load distribution in the entire structure may be appreciably influenced beyond the plastic region. As the loading of the panel is further increased, loads transferred through the fasteners resting on the yielded (plastic regime) surfaces continue to increase considerably slower than loads in fasteners with the bearing stresses still contained within the elastic regime. Consequently, the latter fasteners begin transferring higher load until they themselves exceed yielding stress in their bearing areas. Overall, once the bearing stress starts exceeding the yielding value in some fastener joints, the initially non-uniform distribution of the load between different fasteners begins to equalize.

In the context of the above discussion, it is possible that load distribution in fasteners due to plasticity occurring in some of the fastener holes influenced the far field response in the repair panel. In other words, local plasticity was not adequately considered in the FE analysis to predict accurate local strains as deformation occurred at the fastener holes. It is possible that the analysis produces an erroneous rate of strain growth with increased load in sections of the FE model near highly loaded fasteners. Results consistent with this hypothesis are evident in Figure 26 for the repair angle mid-span flange section and in Figure 29 for the center section of the doubler. On the other hand, sections of the structure further away from highly loaded fasteners are less likely to be affected. It is therefore not surprising that the web section of the repair angle, which does not accommodate any fasteners, produced a better correlation between the FE analysis and test results, as illustrated in Figure 27. Obviously in both, stiffened side angles (Figure 26) and smooth side doubler (Figure 29) the behavior attributable to the yielding of fastener bearing surfaces can be associated with strain curves departing from the linear behavior for loads greater than approximately 140-150 kip. Departures from the linear behavior noticeable in Figure 26 and Figure 29 at the lower load levels (30-50 kip range) are possibly attributable to initial slipping of the bolted repair. Finally, the slight mismatches of the load levels where the curves in Figure 26 and Figure 29 display noticeable slope changes can be explained by the lack of the through-the-thickness symmetry in the panel. The presence of countersink in the doubler and its absence in the two repair angles may also contribute to these differences. 


\section{F. Design allowables}

In previous design efforts and trade studies involving PRSEUS panels, stresses associated with bolted repairs were regarded as limiting design criteria. Therefore, the working stress allowable in any region that might require repair was limited to $55 \mathrm{ksi}$. Recent repair design and analysis efforts ${ }^{10,11}$ aimed to challenge the conservativeness of the $55 \mathrm{ksi}$ tension allowable by assuming a $60 \mathrm{ksi}$ target. As indicated before, the tension panel configuration considered in this study with the $60 \mathrm{ksi}$ working stress allowable target resulted in a DUL of $178.7 \mathrm{kip},{ }^{11}$ whereas the $55 \mathrm{ksi}$ allowable would result in a DUL of 163.8 kip. The experimental study described herein provided an opportunity not only to validate the $60 \mathrm{ksi}$ working stress allowable but also to explore feasibility of adopting even higher design allowables. When the maximum test load of $244.0 \mathrm{ksi}$ was reduced by the customary statistical scatter factor of $15 \%$, the prorated failure load of 207.4 kip was obtained. This load corresponds to a working stress allowable of $69.6 \mathrm{ksi}$, which represents a $26.5 \%$ improvement compared to the original $55 \mathrm{ksi}$ design value. This increase in design allowable should lead to the design of a considerably lighter airframe sustaining the same design loads.

\section{Concluding Remarks}

Applicability of metallic repairs to stiffened composite panels containing severe but localized damage was investigated within the ERA project as an important part of the PRSEUS concept development. A metallic bolted repair was imposed as a design constraint because of its ease of application in the current operational environment. Previously accomplished design and FE analysis efforts were subjected to validation testing.

Generally, aircraft repairs are required to return the structure to its full load carrying capability by allowing the repaired panel to support the DUL of the original pristine panel. In this study, the repaired assembly sustained DLL without experiencing any visible damage or yielding in its metallic repair components, and exceeded DUL prior to final failure of the panel. The repaired panel failed away from the damaged and repaired section, further substantiating the ability of the repair to exceed the load carrying capabilities of the pristine structure. Thus far, PRSEUS panels had been sized using a $55 \mathrm{ksi}$ tension stress allowable due to the concern that it would not be possible to repair damaged panels such that they could sustain loads corresponding to higher allowables. This test provided grounds to consider revision of the tension design allowable to $69.6 \mathrm{ksi}$, i.e., $26.5 \%$ higher. Upward revision of the working stress allowable implies the possibility of designing lighter structure sustaining the same design load levels.

For most of the examined locations, good strain correlation between FE analysis and test results was obtained beyond DLL. As the load increased, the panel began experiencing localized damages, generally permitted in aircraft certification process for load greater than DLL. Since damage progression studies exceeded the scope of the repair design effort, detailed damage progression was not considered in the FE analysis. While initial minor damages did not have a substantial impact on the global panel behavior, FE predictions departed more significantly from the test results as the final failure load was approached. Primary damage modes not considered in the FE analysis, but having appreciable effect on panel behavior before failure, were crack developments in the skin section of the panel, especially near the frame caps, delamination of the pultruded rod from its overwrap in the severed stringer, and bearing stresses exceeding yielding stress value in the metallic repair fastener holes. While FE modeling techniques accounting for all the above-listed factors are available, computational expense associated with this level of analysis fidelity may render it prohibitive in the design and optimization effort where several different configurations must be explored, and such analysis was beyond the scope of this study. The FE modeling practices employed in the presented analysis appear to be adequate for future use in PRSEUS repair design efforts, however, may be not sufficient for other less damage tolerant structures.

\section{Acknowledgments}

The authors wish to thank Kim Linton and Alex Velicki (The Boeing Company) and Andrew Lovejoy (NASA LaRC) for their helpful discussions during the entire course of this work. The authors also gratefully acknowledge David Dawicke (Analytical Services and Materials, Inc.) and Patrick McNeill (Northrop Grumman Corporation) for their support of the test activity. 


\section{References}

${ }^{1} \mathrm{Li}$, V. and Velicki, A., "Advanced PRSEUS Structural Concept Design and Optimization," Proceedings of the 12th AIAA/ISSMO Multidisciplinary Analysis and Optimization Conference, AIAA-2008-5840, Victoria, BC, Canada, 2008.

${ }^{2}$ Jegley, D. C., Velicki, A., and Hansen, D. A., "Structural Efficiency of Stitched Rod-Stiffened Composite Panels with Stiffener Crippling," Proceedings of the 49th AIAA/ASME/ASCE/AHS/ASC Structures, Structural Dynamics and Materials Conference, AIAA-2008-2170, Schaumburg, IL, 2008.

${ }^{3}$ Velicki, A., Thrash, P., and Jegley, D. C., "Airframe Development for the Hybrid Wing Body Aircraft," Proceedings of the 47th AIAA Aerospace Sciences Meeting Including The New Horizons Forum and Aerospace Exposition, AIAA-2009-932, Orlando, FL, 2009.

${ }^{4}$ Yovanof, N. P., Velicki A., and Li, V., "Advanced Structural Stability Analysis of a Nonlinear BWB-Shaped Vehicle," Proceedings of the 50th AIAA/ASME/ASCE/AHS/ASC Structures, Structural Dynamics and Materials Conference, AIAA-2009-2452, Palm Springs, CA, 2009.

${ }^{5}$ Velicki, A. and Thrash, P., "Advanced Structural Concept Development Using Stitched Composites," Proceedings of the 49th AIAA/ASME/ASCE/AHS/ASC Structures, Structural Dynamics and Materials Conference, AIAA-2008-2329, Schaumburg, IL, 2008.

${ }^{6}$ Velicki, A., "Damage Arresting Composites for Shaped Vehicles, Phase I Final Report," NASA CR-2009215932, NASA Langley Research Center, Hampton, VA, September 2009.

${ }^{7}$ Lovejoy, A. E., Rouse, M., Linton, K. A., and Li, V.P., "Pressure Testing of a Minimum Gauge PRSEUS Panel," Proceedings of the 52nd AIAA/ASME/ASCE/AHS/ASC Structures, Structural Dynamics and Materials Conference, AIAA-2011-1813, Denver, CO, 2011.

${ }^{8}$ Velicki, A., Yovanof, N. P., Baraja, J., Linton, K., Li, V., Hawley, A., Thrash, P., DeCoux, S., and Pickell, R., "Damage Arresting Composites for Shaped Vehicles - Phase II Final Report," NASA CR-2011-216880, NASA Langley Research Center, Hampton, VA, January 2011.

${ }^{9}$ Velicki, A. and Jegley, D. C., "PRSEUS Development for the Hybrid Wing Body Aircraft," Proceedings of the AIAA Centennial of Naval Aviation Forum "100 Years of Achievement and Progress," AIAA-2011-7025, Virginia Beach, VA, 2011.

${ }^{10}$ Przekop, A., "Design and Analysis of a Stiffened Composite Structure Repair Concept," Proceedings of the 52nd AIAA/ASME/ASCE/AHS/ASC Structures, Structural Dynamics and Materials Conference, AIAA-2011-1912, Denver, CO, 2011.

${ }^{11}$ Przekop, A., "Repair Concepts as Design Constraints of a Stiffened Composite PRSEUS Panel," Proceedings of the 53rd AIAA/ASME/ASCE/AHS/ASC Structures, Structural Dynamics and Materials Conference, AIAA-2012-1444, Honolulu, HI, 2012.

${ }^{12}$ Composite Aircraft Structure, Advisory Circular AC No. 20-107B, U.S. Department of Transportation, Federal Aviation Administration, August 2010.

${ }^{13}$ Mirsamadi, S., "Advanced Subsonic Technology (AST) Composite Wing Material Stiffness and Allowable Strength Properties for Stitched Composite Laminates," Report Number 98K0318 (proprietary), The Boeing Company, Advanced Transport Aircraft Development, Long Beach, CA, September 1998.

${ }^{14}$ Title 14 Code of Federal Regulation, Part 25 "Airworthiness Standards: Transport Category Airplanes," Subpart C "Structure," §25.305, Electronic Code of Federal Regulations, http://ecfr.gpoaccess.gov

${ }^{15}$ ABAQUS version 6.11 On-line Documentation, ABAQUS Analysis User's Manual, Dassault Systemes Simulia Corp., Providence, RI, 2011.

${ }^{16}$ MD/MSC Nastran 2010 Quick Reference Guide, MSC Software Corporation, Santa Ana, CA, 2010.

${ }^{17}$ McGowan, D. M., Ambur, D. R., and McNeil, S. R., "Full-field Structural Response of Composite Structures: Analysis and Experiment," Proceedings of the 44th AIAA/ASME/ASCE/AHS/ASC Structures, Structural Dynamics and Materials Conference, AIAA 2003-1623, Norfolk, VA, 2003. 